DOI: $10.1002 /$ adfm.201503732

Journal: Advanced Functional Materials

\title{
Energy Quantization in Solution-Processed Layers of Indium Oxide and Their Application in Resonant Tunneling Diodes
}

John G. Labram*, Neil D. Treat, Yen-Hung Lin, Claire H. Burgess, Martyn A. McLachlan Thomas D. Anthopoulos*

Dr. J. G. Labram, Dr Y.-H. Lin, Prof. T. D. Anthopoulos

Department of Physics

Blackett Laboratory

Imperial College London

London, SW7 2AZ, United Kingdom

E-mail: t.anthopoulos@imperial.ac.uk, j.labram@imperial.ac.uk

Dr Y.-H. Lin

Dutch Polymer Institute (DPI)

P.O. Box 902

5600 AX Eindhoven

The Netherlands

Dr. N. D. Treat, Miss C. H. Burgess, Dr. M. McLachlan

Department of Materials

Royal School of Mines

Imperial College London

London, SW7 2AZ

United Kingdom

Keywords: Solution-Processing, Metal Oxide Semiconductors, Indium Oxide, Energy Quantization, Resonant Tunneling Diodes

\begin{abstract}
We study the formation of quantized energy states in ultra-thin layers of indium oxide $\left(\mathrm{In}_{2} \mathrm{O}_{3}\right)$ grown via spin-coating and thermally annealed at $200{ }^{\circ} \mathrm{C}$ in air. Optical absorption measurements reveal a characteristic widening of the optical band gap with reducing $\mathrm{In}_{2} \mathrm{O}_{3}$ layer thickness from $\sim 43 \mathrm{~nm}$ to $\sim 3 \mathrm{~nm}$ in agreement with theoretical predictions for an infinite quantum-well. Through sequential deposition of $\mathrm{In}_{2} \mathrm{O}_{3}$ and gallium oxide $\left(\mathrm{Ga}_{2} \mathrm{O}_{3}\right)$ layers, we demonstrate superlattice-like structures with controlled dimensionality and spatially-varying conduction band characteristics. This simple method is then explored for the fabrication of fully-functional double-barrier resonant tunneling diodes. Nanoscale current mapping analysis using conductive atomic force microscopy, reveal that resonant-tunneling is not uniform but localized in specific regions of the apparent device area. The latter observation is attributed to variation in the layer(s) thickness of the $\mathrm{In}_{2} \mathrm{O}_{3}$ quantum-well and/or the $\mathrm{Ga}_{2} \mathrm{O}_{3}$ barrier layers. Despite the non-idealities, our work demonstrates the tremendous potential of solution-processable oxide semiconductors for the development of quantum-effect devices that have so far been realized only via sophisticated growth techniques.
\end{abstract}




\section{Introduction}

In the last two decades much work has been carried out on two-dimensional electron gases (2DEGs) formed at the interface between certain atomically flat, highly-crystalline polar oxides grown via techniques such as molecular beam epitaxy (MBE) or pulsed laser deposition (PLD). ${ }^{1-3}$ This has subsequently lead to the demonstration of a range of interesting properties such as extremely high charge carrier mobilities, ${ }^{4,5}$ strong-correlation phenomena ${ }^{6}$ and high-temperature superconductivity. ${ }^{7-9}$ In an analogous approach, recent evidence of carrier energy quantization has been reported at the interfaces between metal oxides such as $\mathrm{Mg}_{\mathrm{x}} \mathrm{Zn}_{1-\mathrm{x}} \mathrm{O} / \mathrm{ZnO}$ deposited via radiofrequency (RF) sputtering $^{10,11}$ as well as between disordered $\mathrm{SrTiO}_{3}$ on ordered $\mathrm{LaAlO}_{3}{ }^{12}$ Optical studies of metal oxide superlattices formed from alternating layers of RF-sputtered gallium-indium-zinc-oxide (GIZO) and $\mathrm{Ga}_{2} \mathrm{O}_{3}$ have also provided strong evidence of energy quantization in this relatively unexplored family of electronic materials. ${ }^{13}$ Similarly, recent reports of ultra-thin $(<5 \mathrm{~nm})$ and highly conformal layers of $\mathrm{ZnO}$ and $\mathrm{In}_{2} \mathrm{O}_{3}$ grown from solution ${ }^{14,15}$ have opened the door to the possibility of carrier energy quantization in solution-processed semiconductors and recent studies have provided the first experimental evidence that this is indeed possible. ${ }^{15,}{ }^{16}$ Despite the tremendous potential of the metal oxide technology, however, reports on energy quantization phenomena and their possible exploitation for practical device applications, remain surprisingly limited.

Thin film electronics based on solution-processed metal-oxide semiconductors present academia and industry with the remarkable opportunity to create a new generation of lowcost, large-area electronics, potentially compatible with temperature-sensitive flexible substrates. ${ }^{17,18}$ Whilst the performance of solution-processed metal-oxide thin-film transistors (TFTs) is already superior to most competing technologies, ${ }^{19}$ the ability to control and manipulate energy quantization phenomena in solution-processable oxide semiconductors 
opens the possibility to realize a wide range of unique and highly novel applications, granting device physicists and engineers a whole new region of parameter space to explore.

Here we report on energy quantization phenomena observed in ultra-thin layers of $\mathrm{In}_{2} \mathrm{O}_{3}$ grown from solution in ambient air at temperatures $\leq 200{ }^{\circ} \mathrm{C}$. Optical absorption measurements reveals a systematic widening of the optical band gap of $\operatorname{In}_{2} \mathrm{O}_{3}$ with reducing layer thickness from $\sim 43 \mathrm{~nm}$ down to $\sim 3 \mathrm{~nm}$ in agreement with theoretical predictions for an infinite quantum well $(\mathrm{QW}) .^{20,21}$ Through sequential deposition of $\operatorname{In}_{2} \mathrm{O}_{3}$ and the wide band gap material gallium oxide $\left(\mathrm{Ga}_{2} \mathrm{O}_{3}\right)$, we show that multilayer oxide structures with controlled dimensionality and spatially-varying conduction band characteristics can indeed be grown from solution at this rather low temperature. By exploring these unique attributes together with carefully designed device architectures, we are able to demonstrate functional resonant tunneling diodes (RTDs). ${ }^{22,} 23$ As-prepared RTDs exhibit highly reproducible negative differential conductance (NDC) in both biasing directions. Current mapping analysis of the RTDs' active region using conductive atomic force microscopy (CAFM) reveals that resonant tunneling is not uniform but it is localized in certain regions. The latter variation is argued to be due to the non-uniformities in the layer thickness of the solution processed $\operatorname{In}_{2} \mathrm{O}_{3}$ and $\mathrm{Ga}_{2} \mathrm{O}_{3}$

\section{Energy Level Quantization in Solution-Deposited Ultra-Thin Layers of $\operatorname{In}_{2} \mathrm{O}_{3}$}

Initial experiments focused on the deposition of several $\mathrm{In}_{2} \mathrm{O}_{3}$ films on quartz substrates via spin-casting. By adjusting the solution concentration and/or the number of sequential deposition steps (i.e. spin-casting followed by thermal annealing), the thickness of the final metal oxide layer can be controlled with nm resolution. Figures 1(a)-(c) display transmission electron microscopy (TEM) images of three example $\mathrm{In}_{2} \mathrm{O}_{3}$ films grown on quartz. The films 
have mean thicknesses of $\sim 3 \mathrm{~nm}, \sim 8 \mathrm{~nm}$ and $\sim 43 \mathrm{~nm}$, respectively. Here, the $43 \mathrm{~nm}$-thick layer was formed using 6 sequential deposition steps (i.e. spin casting followed by thermal annealing for $30 \mathrm{~min}$ at $200{ }^{\circ} \mathrm{C}$ in air), each of which is easily identifiable in Figure 1 (c) (see also Supporting Information Figure S1). The darker regions between spin-casts are believed to be regions of a different structural phase in the $\operatorname{In}_{2} \mathrm{O}_{3}$, induced during UV-ozone treatment applied before each deposition. Figures 1(d)-(f) show the surface topography of the same three films measured using an atomic-force microscope (AFM), while Figures 1(g)-(i) display the respective height-distributions from each AFM image. The blue lines in Figures 1(g)-(i) are Gaussian fits to the height distributions with standard deviations of $3 \AA, 2 \AA$ and $3 \AA$ respectively. More thorough analysis of the topography of these films (see Supporting Information Section S2) reveals the roughness to be approximately independent of the mean film thickness and suggests subsequent depositions help to planarize the underlying surface. Through large-area AFM scans and TFT measurements, the as-processed $\operatorname{In}_{2} \mathrm{O}_{3}$ films were found to be continuous over large areas and able to sustain substantial electron transporting characteristics (see Supporting Information Sections S2 \& S3).

Figure 2(a) shows optical transmission spectra of several $\operatorname{In}_{2} \mathrm{O}_{3}$ films on quartz substrates with a range of mean film thicknesses. Using Tauc analysis, the optical band gaps of these samples were then extracted (see Supporting Information Section S4). Since the nature of the optical band-gap in $\operatorname{In}_{2} \mathrm{O}_{3}$ is still under debate, ${ }^{24-26}$ techniques assuming both an indirect and direct band gap have been applied here. By approximating films with a mean thickness $>10 \mathrm{~nm}$ as being representative of bulk $\operatorname{In}_{2} \mathrm{O}_{3}$, the change in optical band gap $\left(\Delta E_{G}\right)$ with respect to bulk $\mathrm{In}_{2} \mathrm{O}_{3}$, as a function of mean film thickness can be calculated [see Figure 2(b)]. The red band in Figure 2(B) illustrates the expected change in optical band gap for an infinite $\mathrm{In}_{2} \mathrm{O}_{3}$ quantum well with a finite roughness (details of this distribution are given in Supporting Information Section S5). As previously observed for similar films of $\mathrm{ZnO},{ }^{16}$ we 
Adv. Funct. Mater. (2016); DOI: 10.1002/adfm.201503732

see a strong agreement with theory, once again suggesting the formation of quantized subbands $^{27}$ in these ultra-thin, but yet uniform, films. ${ }^{27}$ The effective masses of electrons and holes for $\mathrm{In}_{2} \mathrm{O}_{3}$ employed in these calculations were $m_{e}^{*}=0.3 m_{e}$ and $m_{h}^{*}=0.6 m_{e}$ respectively, where $m_{e}$ is the rest mass of electrons in vacuum.

\section{Multilayer Solution-Deposited Oxide Structures}

The ability to grow from solution phase such well-defined, ultra-thin layers of metal oxides that exhibit quantized energy states is thought provoking and motivated us to explore the possibility of creating more complex multilayer systems such as alternating superlattices composed of two or more materials. To this end, several groups have previously studied multi-layer solution-processed oxide thin-film transistors (TFTs), ${ }^{28-30}$ all with differing motivations. To investigate this possibility, we deposited single, bilayer and multilayer oxides composed of alternating $\mathrm{In}_{2} \mathrm{O}_{3}$ and $\mathrm{Ga}_{2} \mathrm{O}_{3}$ layers in ambient air at $200{ }^{\circ} \mathrm{C}$. The elemental composition of the various structures was then investigated employing time-of-flight secondary ion-mass spectroscopy (ToF-SIMS). Two examples of metal oxide structures developed are shown in Figures 3(a-b) while additional data for various other structures developed and studied are presented in the Supporting Information Section S6. Each layer was formed of 5 sequential spin cast steps of the respective semiconductor. For example the structure in Figure 3(a) was formed by spin-casting $\operatorname{In}_{2} \mathrm{O}_{3}$ onto polished Si using 5 deposition steps, followed by 5 deposition steps of $\mathrm{Ga}_{2} \mathrm{O}_{3}$ and a further 5 deposition steps of $\operatorname{In}_{2} \mathrm{O}_{3}$. The thickness of the resulting Figure 3(a) and 3(b) multilayer structures were between $90-95 \mathrm{~nm}$ and 130-140 nm, respectively. These values were estimated based on TEM measurements [Figure 1(a-c)] and the number of fringes in the $\mathrm{In}^{+}$signal in the ToF-SIMS depth profiles obtained from these structures [Figures 3(c-d)]. For each stack, the plots show isolated regions of higher Ga concentration, in accordance with the target structures. However closer 
examination of the data suggests that Ga diffuses since elemental signatures of it appear across the multilayer system although layer-thickness variations and/or anisotropic sputtering, may play an important role for this "apparent" diffuse Ga concentration profile. If Ga diffusion is indeed taking place then it can be argued that these regions should be considered to be locally Ga-rich rather than pure Ga layers. This interpretation is further supported by the fact that the In concentration is little affected in the Ga-rich regions, although this may be affected by the non-uniformities in the layer thicknesses. By considering that the samples are annealed for 30 minutes after each solution deposition, and hence that the bottom layers will in total be annealed for longer than those at the top, one can interpret Figure 3(b) as evidence that a temperature-dependent diffusion process is likely to be responsible for this profile. However, further work will be required to either support or refute this proposal. Finally, we observe an initial increase in the signal of In in samples where the top layer is $\operatorname{In}_{2} \mathrm{O}_{3}$ and an increase in $\mathrm{Ga}$ signal in samples where the top layer is $\mathrm{Ga}_{2} \mathrm{O}_{3}$ (see Supporting Information Figure S7). We believe this to be an artifact due to stabilization of the TOF-SIMS signal when the measurement begins, and the fact that we have not employed a capping layer in our structures.

\section{Oxide-Based Quantum-Well Electronic Devices}

Regardless of whether these regions are locally $\mathrm{Ga}_{2} \mathrm{O}_{3}$-pure or not, one can expect significant spatial modulation of the electronic properties in this multilayer structure since $\mathrm{Ga}_{2} \mathrm{O}_{3}$ has a significantly larger band-gap ${ }^{31}$ than $\operatorname{In}_{2} \mathrm{O}_{3}$, and has in the past been employed as a barrier layer in disordered oxide QW structures. ${ }^{13,16,32}$ One possible application of such QW systems and layered structures is in quantum effect electronic devices such as double-barrier resonant tunneling diodes (RTDs). ${ }^{23}$, 32 To test this interesting possibility we fabricated the RTD structure depicted in Figure 4(a) via sequential deposition of the different layers. Figure 4(b) shows an illustration of the assumed conduction band profile across the structure. Here, both 
the $\mathrm{In}_{2} \mathrm{O}_{3}$ and the width of the barriers and the QW itself is assumed to be graded, rather than rectangular, due to the apparent diffusion of Ga seen in Figure 3. Although the height of the offset in conduction bands is unknown, it is anticipated that an ultra-thin layer $(\sim 3 \mathrm{~nm})$ of $\mathrm{In}_{2} \mathrm{O}_{3}$ sandwiched between two $\mathrm{Ga}_{2} \mathrm{O}_{3}$-rich regions should form a QW. In a recent study we have shown that the formed $\mathrm{Ga}_{2} \mathrm{O}_{3}$ layers/barriers are approximately 2.5 nm-thick. ${ }^{15}$ This barrier/QW/barrier system is then sandwiched between two bulk (40 nm-thick) layers of $\operatorname{In}_{2} \mathrm{O}_{3}$ and two metal (Al) Ohmic contacts to form the diode. RTDs are known to exhibit negative differential conductance (NDC) when a potential is applied across the structure. ${ }^{22,32}$ This is due to an enhanced probability of tunneling taking place when the central quantized subbands are resonant with carriers in the bulk $\mathrm{In}_{2} \mathrm{O}_{3}$ regions on either side, and a significant attenuation in all other cases. A more detailed description of the operation of these devices can be found elsewhere, ${ }^{23,32,33}$ but the important point for the purposes of this study is that the operation of RTDs fundamentally relies upon quantized charge carrier states existing within the central $\mathrm{In}_{2} \mathrm{O}_{3} \mathrm{QW}$.

Figure 4(c) displays the forward and reverse current sweeps of an example device as a function of applied voltage across the structure, measured at room temperature under atmospheric pressure in $\mathrm{N}_{2}$. The device exhibits clear NDC features at $\pm 3 \mathrm{~V}$, i.e. in both the forward and reverse bias sweeps. The electron density can be approximated from these I-V characteristics using the field-effect electron mobility (see Supporting Information Section S3) and the device dimensions yielding values on the order of $10^{14} \mathrm{~cm}^{-3}$. To demonstrate the stability of this device, Figure $4(\mathbf{d})$ shows the forward sweeps of the same device measured repeatedly 10 times. The NDC feature is characteristic of such QW structures ${ }^{22,32-35}$ and, provides strong evidence that energy quantization is indeed taking place in these ultra-thin $\mathrm{In}_{2} \mathrm{O}_{3}$ layers, in agreement with the optical measurements shown in Figure 2. The change in position of the peak current before the NDC region was observed to change in an apparently 
random manner between each successive measurement. Although the origin of this variation is at present unclear it is likely to be due to charge de/trapping effects occurring at the critical oxide-oxide heterointerfaces. Since the height of the potential barriers illustrated in Figure 4(b), or their mathematical form, is unknown it is impossible to determine the voltage at which we expect the NDC feature to occur. What we know, however, is that the voltage must be less than twice the height of the potential barrier divided by $e$ - i.e. the fundamental unit of charge. ${ }^{32}$ We can assume that the alloyed $\mathrm{Ga}_{2} \mathrm{O}_{3} / \mathrm{In}_{2} \mathrm{O}_{3}$ barriers have a height less than that of pure $\mathrm{Ga}_{2} \mathrm{O}_{3}$. Given the offset in the conduction band minima of $\mathrm{Ga}_{2} \mathrm{O}_{3}$ and $\mathrm{In}_{2} \mathrm{O}_{3}$ is approximately $1.4 \mathrm{eV},{ }^{16,31}$ we expect the voltage of the NDC feature to occur well below 2.8 V. Since the current is high in our device, we believe it is very likely that voltage will be dropped across other parts of the experimental setup/device e.g. across the thin Al top electrode and/or across the $\mathrm{Al} / \mathrm{In}_{2} \mathrm{O}_{3}$ contact due to the presence of a resistive element. To this end, highly insulating $\mathrm{Al}_{2} \mathrm{O}_{3}$ is known to form on $\mathrm{Al}$ electrodes after thermal annealing. ${ }^{14}$ Detailed investigation of the possible origin of this relatively large resonant voltage is currently under investigation and will be reported in the future. Despite this, however, the $\mathrm{In}_{2} \mathrm{O}_{3}$-based RTDs are simple and easy to fabricate with high yield, hence making the technology potentially attractive for numerous applications.

\section{Conducting Atomic Force Microscopy of Oxide Quantum Well Devices}

To study these devices more thoroughly, CAFM measurements were carried out. Similar structures to those described in Figure 4(a) were fabricated, but with the deposition of the top aluminum electrode omitted. A conductive Ti/Pt cantilever [CAFM tip in Figure 5(a)] was then used as the top electrode, enabling current-voltage (I-V) characteristics to be measured as a function of $x y$-position with $\mathrm{nm}$ resolution. Representative $\mathrm{I}-\mathrm{V}$ characteristics at three different positions on a single device are presented in Figures 5(b-d). Although there are clear position-to-position variations, NDC can again be observed in both voltage quadrants 
Adv. Funct. Mater. (2016); DOI: 10.1002/adfm.201503732

$\left(1^{\text {st }}\right.$ and $\left.3^{\text {rd }}\right)$. For voltages higher than $\pm 2 \mathrm{~V}$ the current saturates as the compliance of the system used was $10 \mathrm{nA}$. By differentiating each curve and extracting the minimum value of conductance, we are able to plot the peak NDC as a function of $x y$ position. Representative data are shown in Figure 5 (e-g) where the maximum values of NDC are plotted as a function of $x y$ position for positive bias, negative bias and both current maps combined (i.e. the sum of the positive and negative maps), respectively.

Whilst there are clearly variations in the magnitude of the measured NDC, this data reveals some very useful information. By considering positions where the peak NDC $\geq 5 \mathrm{nS}$ as "working" and those with peak NDC $<5 \mathrm{nS}$ as "non-working", one can produce a binary map (i.e. 1's and 0's) to represent "working" and "non-working" positions, respectively, on the apparent active area of the device (see Supporting Information Figure S9). The correlation between these values was evaluated as described in Supporting Information Section S7 to be +0.155 , meaning that if NDC were to appear in one quadrant it should on average appear in the other. This value was found to be more than 3 standard deviations from the mean of a set of 1,000,000 randomly distributed 1's and 0's. Further discussion on the significance of the magnitude of the correlation is provided in the Supporting Information. This positive correlation suggests that the devices are structurally symmetric with their electronic properties determined primarily by the local structure rather than the biasing conditions employed. This experimental evidence reduces the number of alternative descriptions for the observed NDC features in our devices. The variation with NDC as a function of position is attributed to the fact that the layers have a finite, albeit rather low, roughness, as described in Section S2 of the Supporting Information. 
Adv. Funct. Mater. (2016); DOI: 10.1002/adfm.201503732

\section{Conclusions}

In summary we have presented strong evidence of the existence of quantized carrier states in ultra-thin, solution-processed $\mathrm{In}_{2} \mathrm{O}_{3}$ layers. TEM, AFM and electrical field-effect measurements reveal the formation of continuous, highly-uniform semiconducting layers with controllable thicknesses in the range of 3-43 nm. The optical band-gaps of these layers are found to increase as their thicknesses is reduced, in agreement with carrier-confinement. Sequential deposition of $\operatorname{In}_{2} \mathrm{O}_{3}$ and $\mathrm{Ga}_{2} \mathrm{O}_{3}$ layers indicates the formation of locally Ga-rich regions as observed by ToF-SIMS. This property is then exploited to form a structure consisting of a spatially varying conduction band such as double-barrier resonant tunneling diodes. Electrical measurements reveal the presence of a highly-reproducible and stable NDC feature for the vast majority of RTDs tested - a feature that is absent from all control diodes fabricated in parallel. Conducting AFM measurements carried out on similar device but with the top Al electrode now being replaced by the conductive AFM tip, allowed the NDC to be mapped as a function of $x y$ position on the device's surface. Analysis of this data has revealed a positive correlation between positive and negative voltages. This work contributes to a mounting body of evidence that 2D-transport phenomena can indeed be observed in solutionprocessed oxide semiconductors potentially paving the way to interesting technological applications.

\section{Experimental Section}

\section{Solution preparation and processing}

Anhydrous indium nitrate $\left(\operatorname{In}\left(\mathrm{NO}_{3}\right)_{3}, 99.99 \%\right.$ Indium Corporation) was dissolved in 2 methoxyethanol at a range of concentrations between of $10 \mathrm{mg} / \mathrm{ml}$ and $40 \mathrm{mg} / \mathrm{ml}$. Gallium nitrate hydrate $\left(\mathrm{Ga}\left(\mathrm{NO}_{3}\right)_{3} \cdot \times \mathrm{H}_{2} \mathrm{O}, 99 \%\right.$ Sigma-Aldrich) was dissolved in deionized water at a concentration of $12 \mathrm{mg} / \mathrm{ml}$. The solutions were left stirring overnight at room-temperature 
Adv. Funct. Mater. (2016); DOI: 10.1002/adfm.201503732

before deposition. Solutions were deposited via spin-casting under ambient-pressure air at 4,000 rpm. Films were then annealed at $200^{\circ} \mathrm{C}$ for 30 minutes after each deposition. Samples were subject to UV-ozone treatment before each spin cast.

Transmission electron microscopy (TEM)

Cross-sections for imaging were prepared using a FEI Helios Nanolab DualBeam focused ion beam (FIB)/scanning electron microscope (SEM). The FIB was operated successively at accelerating voltages of $30 \mathrm{kV}, 5 \mathrm{kV}$ and $2 \mathrm{kV}$, and the SEM operated at $5 \mathrm{kV}$. The transmission electron microscope (TEM) images were acquired using a JEOL JEM-2100F TEM operating at $200 \mathrm{kV}$ accelerating voltage.

Atomic force microscopy (AFM)

Atomic force microscopy was carried out in tapping mode using an Agilent 5500 atomic force microscope in ambient atmosphere. The approximate resonance frequency of the cantilever was $250 \mathrm{kHz}$ and the force constant was approximately $60 \mathrm{Nm}^{-1}$.

\section{Optical transmittance measurements}

$\mathrm{In}_{2} \mathrm{O}_{3}$ films were spin-cast onto quartz substrates in air. The films were then annealed at $200{ }^{\circ} \mathrm{C}$ for 30 minutes in air. Measurements were carried out with a Shimadzu UV-2600 ultraviolet-visible spectrophotometer. Transmittance and reflectance measurements were carried out for each sample. The transmittance corrected for reflectance was derived from the transmittance + reflectance.

Time-of-flight secondary ion mass spectrometry (TOF-SIMS)

An Ion TOF 5 SIMS at $10^{-8}$ torr was used to measure depth profiles with a $1 \mathrm{kV} \mathrm{Cs}^{+}(\sim 45 \mathrm{nA})$ sputter beam rastered across a $400 \times 400 \mu \mathrm{m}$ square. Positive ions were collected from the central $100 \times 100 \mu \mathrm{m}$ of the sputter crater using a $\mathrm{Bi}_{3}{ }^{+}(\sim 1 \mathrm{pA})$ beam with charge compensation.

Fabrication of resonant tunneling diodes 
Adv. Funct. Mater. (2016); DOI: 10.1002/adfm.201503732

Resonant tunneling diodes (RTDs) were fabricated on glass substrates. $50 \mathrm{~nm}$ aluminum bottom electrodes were deposited via thermal evaporation under high vacuum, through shadow masks at an average rate of $0.5 \AA^{-1}$. A bulk $\mathrm{In}_{2} \mathrm{O}_{3}$ layer was deposited by 5 sequential spin-casting and thermal annealing steps. After each spin-casting step the samples were annealed at $200{ }^{\circ} \mathrm{C}$ for 30 minutes in air. Next a $\mathrm{Ga}_{2} \mathrm{O}_{3}$-barrier layer was deposited on top of the bottom bulk $\mathrm{ZnO}$ layer. Two sequential spin-casts of $\mathrm{Ga}_{2} \mathrm{O}_{3}$ were carried out employing the gallium nitrate hydrate solution described in Section S1.1. Again, the samples were then annealed at $200{ }^{\circ} \mathrm{C}$ for 30 minutes in air after each deposition. A single $\operatorname{In}_{2} \mathrm{O}_{3}$ layer was then spin-cast onto the bottom barrier layer. A concentration and spinning speed were used that gave rise to a mean thickness of $3.0 \mathrm{~nm}$ when a single layer was deposited onto quartz. The samples were again annealed at $200{ }^{\circ} \mathrm{C}$ for 30 minutes in air. A second barrier layer of $\mathrm{Ga}_{2} \mathrm{O}_{3}$ was then applied on top of the thin $\operatorname{In}_{2} \mathrm{O}_{3}$ layer in an identical manner as described above for the bottom barrier layer. A second bulk $\operatorname{In}_{2} \mathrm{O}_{3}$ layer was deposited on top of the second barrier layer via 5-sequential spin-castings steps, as described above for the bottom bulk $\mathrm{In}_{2} \mathrm{O}_{3}$ layer. Finally, $50 \mathrm{~nm}$ aluminum top electrodes were deposited via thermal evaporation under high vacuum through shadow masks at an average rate of $0.5 \AA \mathrm{s}^{-1}$. Electrical characterization was carried out at room temperature under ambient pressure in nitrogen using an Agilent B2902A semiconductor parameter analyzer. The device areas of RTDs ranged from $0.0625 \mathrm{~mm}^{2}$ to $0.5 \mathrm{~mm}^{2}$.

\section{Conducting atomic force microscopy (CAFM)}

Resonant tunneling diode devices were fabricated as described above but with the final top Al electrode deposition step omitted. Current-voltage (IV) measurements were carried out as a function of surface position using an Agilent 5500 atomic force microscope in ambient atmosphere. A titanium / platinum cantilever was used in contact mode and a voltage was applied between the cantilever and the bottom aluminum electrode. The compliance of this system was $10 \mathrm{nA}$. The negative differential conductance (NDC) was evaluated from each I-V 
measurement using 11-point differentiation. The peak value of NDC for each I-V curve was then extracted for positive and negative voltages. To reduce artefacts, the lowest positive and negative voltages that gave rise to currents above compliance were noted, and the IV curve was only considered between these values.

\section{Supporting Information}

Supporting Information is available from the Wiley Online Library or from the author.

\section{Acknowledgements}

J.G.L. Y.H.L. J.S. and T.D.A. are grateful to Dutch Polymer Institute (DPI) S-PLORE grant no. 735 and European Research Council (ERC) AMPRO project no. 280221 for financial support. 
Adv. Funct. Mater. (2016); DOI: 10.1002/adfm.201503732

\section{References}

[1] A. Ohtomo, H. Y. Hwang, Nature 2004, 427, 423.

[2] S. Thiel, G. Hammerl, A. Schmehl, C. W. Schneider, J. Mannhart, Science 2006, 313, 1942.

[3] A. Tsukazaki, A. Ohtomo, T. Kita, Y. Ohno, H. Ohno, M. Kawasaki, Science 2007, $315,1388$.

[4] Y. Kozuka, A. Tsukazaki, D. Maryenko, J. Falson, S. Akasaka, K. Nakahara, S. Nakamura, S. Awaji, K. Ueno, M. Kawasaki, Phys Rev B 2011, 84, 033304.

[5] F. Joseph, M. Denis, K. Yusuke, T. Atsushi, K. Masashi, Applied Physics Express $2011,4,091101$.

[6] J. Mannhart, D. G. Schlom, Science 2010, 327, 1607.

[7] N. Reyren, S. Thiel, A. D. Caviglia, L. F. Kourkoutis, G. Hammerl, C. Richter, C. W. Schneider, T. Kopp, A.-S. Rüetschi, D. Jaccard, M. Gabay, D. A. Muller, J.-M. Triscone, J. Mannhart, Science 2007, 317, 1196.

[8] A. Gozar, G. Logvenov, L. F. Kourkoutis, A. T. Bollinger, L. A. Giannuzzi, D. A. Muller, I. Bozovic, Nature 2008, 455, 782.

[9] G. Logvenov, A. Gozar, I. Bozovic, Science 2009, 326, 699.

[10] H.-A. Chin, I.-C. Cheng, C.-I. Huang, Y.-R. Wu, W.-S. Lu, W.-L. Lee, J. Z. Chen, K.C. Chiu, T.-S. Lin, J Appl Phys 2010, 108.

[11] I.-C. Cheng, B.-S. Wang, H.-H. Hou, J.-Z. Chen, ECS Transactions 2013, 50, 83.

[12] Y. Chen, N. Pryds, J. e. E. Kleibeuker, G. Koster, J. Sun, E. Stamate, B. Shen, G. Rijnders, S. Linderoth, Nano Lett 2011, 11, 3774.

[13] K. Abe, K. Nomura, T. Kamiya, H. Hosono, Phys Rev B 2012, 86, 081202.

[14] Y.-H. Lin, H. Faber, K. Zhao, Q. Wang, A. Amassian, M. McLachlan, T. D. Anthopoulos, Adv Mater 2013, 25, 4340. 
[15] Y.-H. Lin, H. Faber, J. G. Labram, E. Stratakis, L. Sygellou, E. Kymakis, N. A. Hastas, R. Li, K. Zhao, A. Amassian, N. D. Treat, M. McLachlan, T. D. Anthopoulos, Advanced Science 2015, n/a.

[16] J. G. Labram, Y.-H. Lin, K. Zhao, R. Li, S. R. Thomas, J. Semple, M. Androulidaki, L. Sygellou, M. McLachlan, E. Stratakis, A. Amassian, T. D. Anthopoulos, Adv Funct Mater $2015,25,1727$.

[17] E. Fortunato, P. Barquinha, R. Martins, Adv Mater 2012, 24, 2945.

[18] S. R. Thomas, P. Pattanasattayavong, T. D. Anthopoulos, Chem Soc Rev 2013, 42, 6910.

[19] P. K. Nayak, M. N. Hedhili, D. Cha, H. N. Alshareef, Appl Phys Lett 2013, 103.

[20] A. I. M. Rae, Quantum mechanics, Taylor \& Francis Group, 2008.

[21] C. Weisbuch, B. Vinter, Quantum Semiconductor Structures: Fundamentals and Applications, Academic Press, 1991.

[22] L. L. Chang, L. Esaki, R. Tsu, Appl Phys Lett 1974, 24, 593.

[23] H. Mizuta, T. Tanoue, The Physics and Applications of Resonant Tunnelling Diodes, Cambridge University Press, 2006.

[24] P. Erhart, A. Klein, R. G. Egdell, K. Albe, Phys Rev B 2007, 75, 153205.

[25] A. Walsh, J. L. F. Da Silva, S.-H. Wei, C. Körber, A. Klein, L. F. J. Piper, A. DeMasi, K. E. Smith, G. Panaccione, P. Torelli, D. J. Payne, A. Bourlange, R. G. Egdell, Phys Rev Lett 2008, 100, 167402.

[26] P. D. C. King, T. D. Veal, F. Fuchs, C. Y. Wang, D. J. Payne, A. Bourlange, H. Zhang, G. R. Bell, V. Cimalla, O. Ambacher, R. G. Egdell, F. Bechstedt, C. F. McConville, Phys Rev B 2009, 79, 205211.

[27] R. Dingle, W. Wiegmann, C. H. Henry, Phys Rev Lett 1974, 33, 827.

[28] Y. S. Rim, H. Chen, X. Kou, H.-S. Duan, H. Zhou, M. Cai, H. J. Kim, Y. Yang, Adv Mater 2014, 26, 4273. 
[29] X. Yu, N. Zhou, J. Smith, H. Lin, K. Stallings, J. Yu, T. J. Marks, A. Facchetti, ACS Applied Materials \& Interfaces 2013, 5, 7983.

[30] Y.-H. Lin, H. Faber, E. Stratakis, L. Sygellou, E. Kymakis, N. A. Hastas, R. Li, K.

Zhao, A. Amassian, N. D. Treat, M. McLachlan, T. D. Anthopoulos, In Press 2014.

[31] S. R. Thomas, G. Adamopoulos, Y.-H. Lin, H. Faber, L. Sygellou, E. Stratakis, N.

Pliatsikas, P. A. Patsalas, T. D. Anthopoulos, Appl Phys Lett 2014, 105.

[32] R. Tsu, L. Esaki, Appl Phys Lett 1973, 22, 562.

[33] S. Jian Ping, G. I. Haddad, P. Mazumder, J. N. Schulman, Proceedings of the IEEE $1998,86,641$.

[34] C. I. Huang, M. J. Paulus, C. A. Bozada, S. C. Dudley, K. R. Evans, C. E. Stutz, R. L. Jones, M. E. Cheney, Appl Phys Lett 1987, 51, 121.

[35] T. C. L. G. Sollner, W. D. Goodhue, P. E. Tannenwald, C. D. Parker, D. D. Peck, Appl Phys Lett 1983, 43, 588 . 

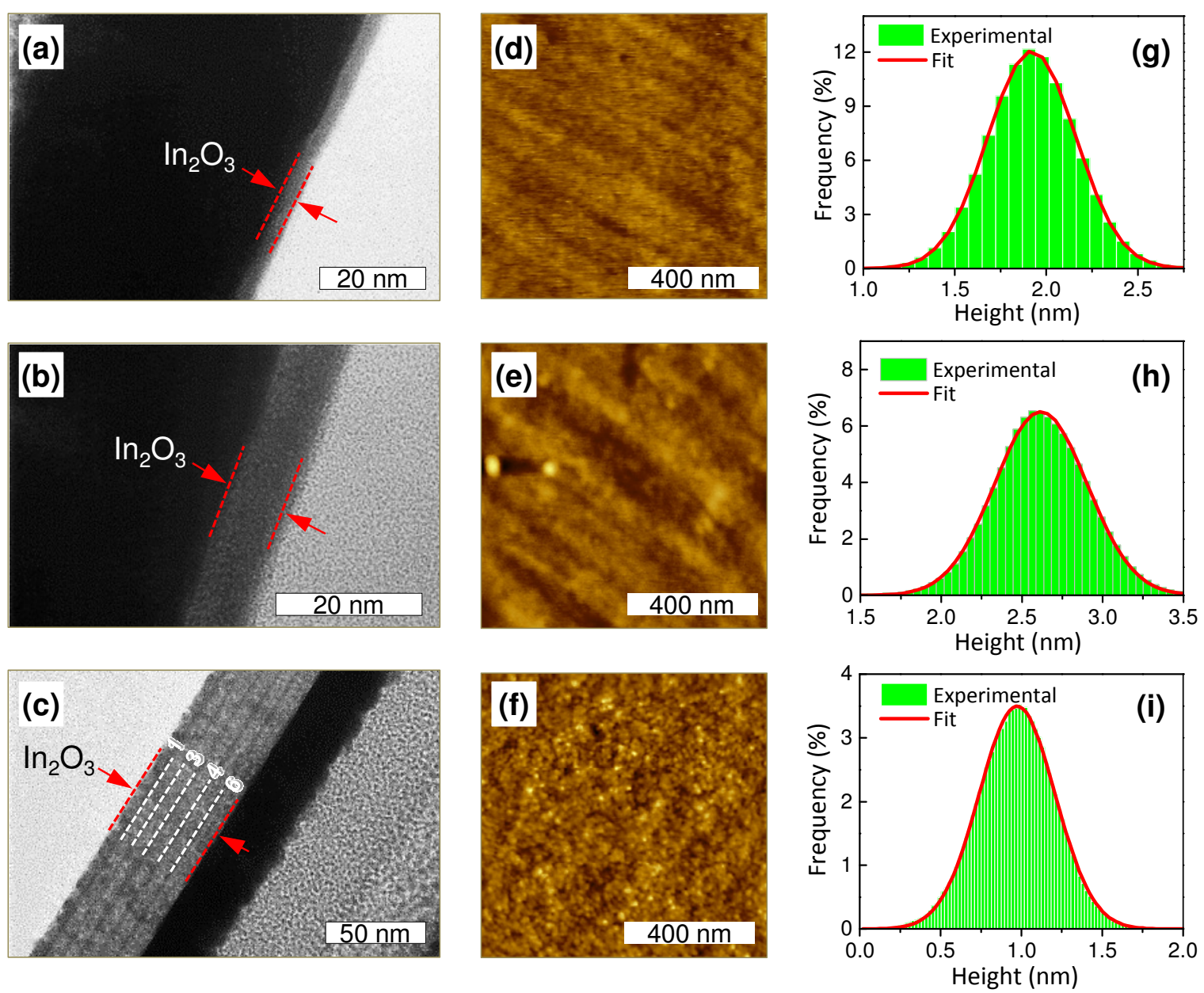

Figure 1. (a-c) Transmission electron microscope images of three example $\operatorname{In}_{2} \mathrm{O}_{3}$ films spincast onto quartz with mean thicknesses of $\sim 3 \mathrm{~nm}, \sim 8 \mathrm{~nm}$ and $\sim 43 \mathrm{~nm}$ respectively. In (a) and (b) the light regions on the right are the quartz substrates and the dark region on the left are the gold capping layers. In (c) the light region on the left is the quartz substrate and the dark region on the right is the first (gold) capping layer, followed by other capping layers. (d-f) Surface topography of same $\operatorname{In}_{2} \mathrm{O}_{3}$ films from (a-c) respectively measured over an area of 1 $\mu \mathrm{m} \times 1 \mu \mathrm{m}$ using atomic force microscopy (AFM). (g-i) Height distributions extracted from (d-f) respectively. The solid blue line is a Gaussian distribution fitted to the experimental data. 

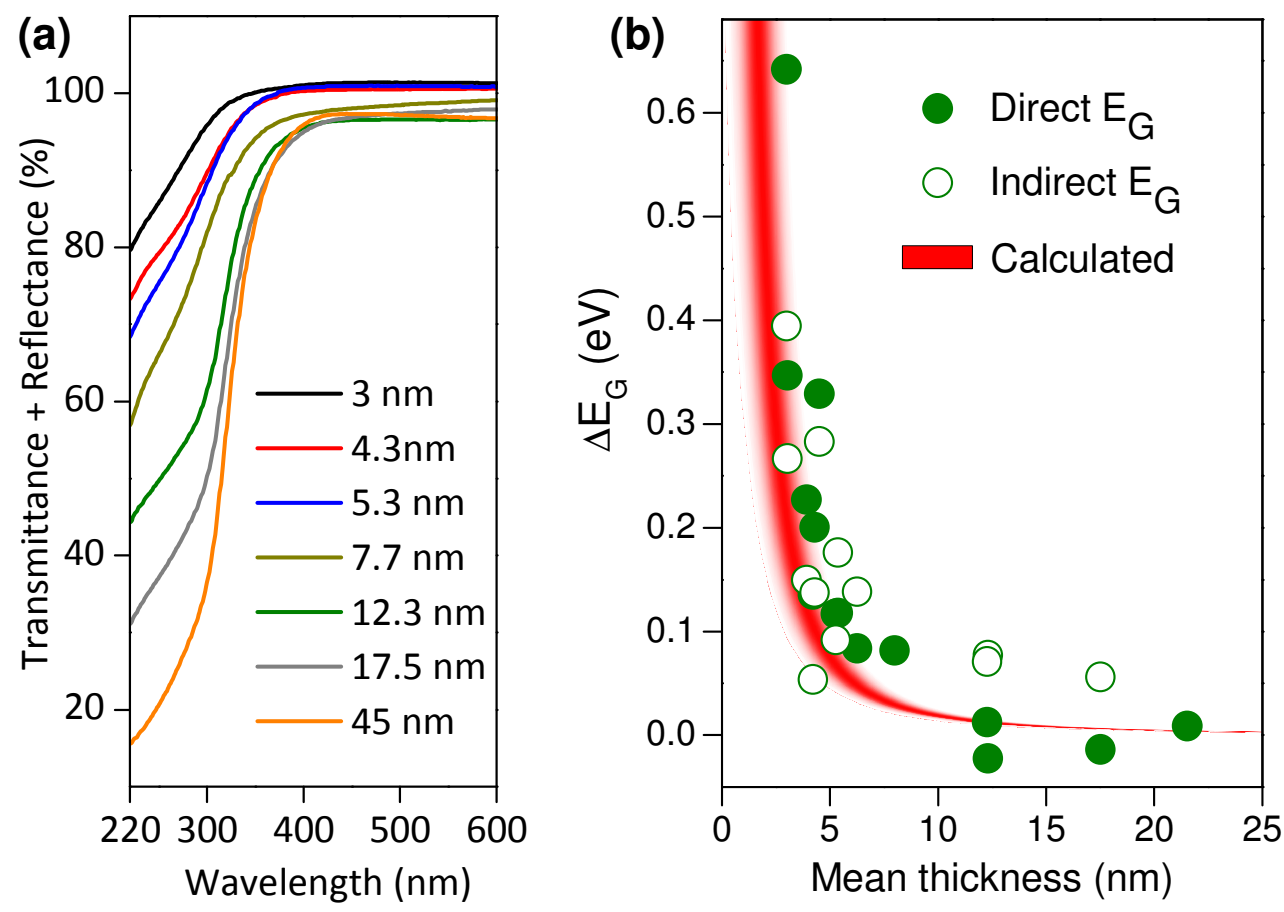

Figure 2. (a) Optical transmittance spectra of several $\mathrm{In}_{2} \mathrm{O}_{3}$ films of various mean thickness deposited onto quartz via spin-casting. All spectra are adjusted for reflectance. (b) Change in optical band gap of several spin-cast $\mathrm{In}_{2} \mathrm{O}_{3}$ films as a function of mean film thickness approximated via Tauc analysis. Due to debate over the nature of the band gap in $\operatorname{In}_{2} \mathrm{O}_{3}$, the change in band gap has been calculated using techniques for both direct and indirect band gap semiconductors. The red band illustrates the expected change in optical band gap for an infinite $\mathrm{In}_{2} \mathrm{O}_{3}$ quantum well of the given mean thickness with a standard deviation of $0.5 \AA$ (estimated experimentally). Red represents the most probable energy for a given mean thickness whilst white represents and energy with a probability zero. For the purposes of this study bulk $\mathrm{In}_{2} \mathrm{O}_{3}$ was considered to be layers with a mean thickness $>10 \mathrm{~nm}$. 
(a)

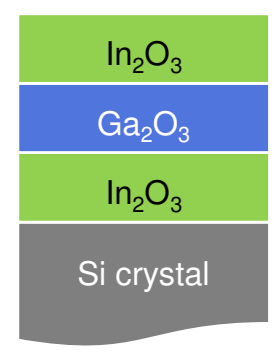

(b)

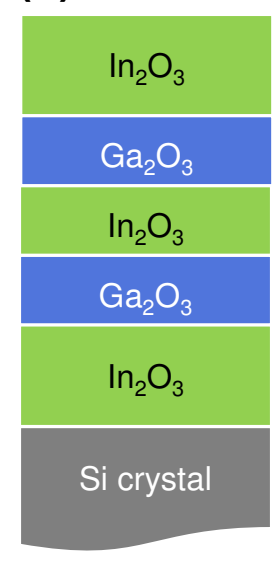

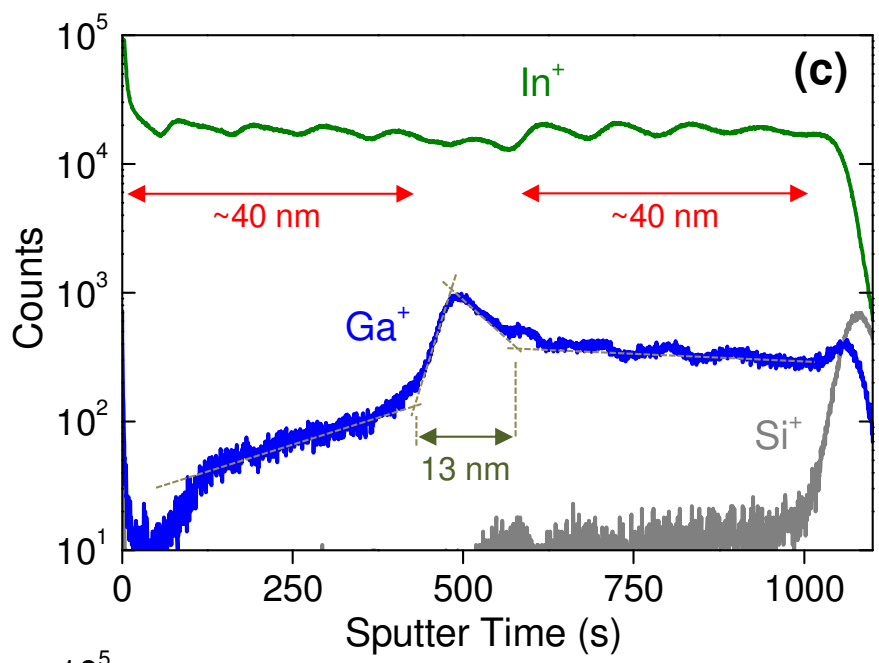

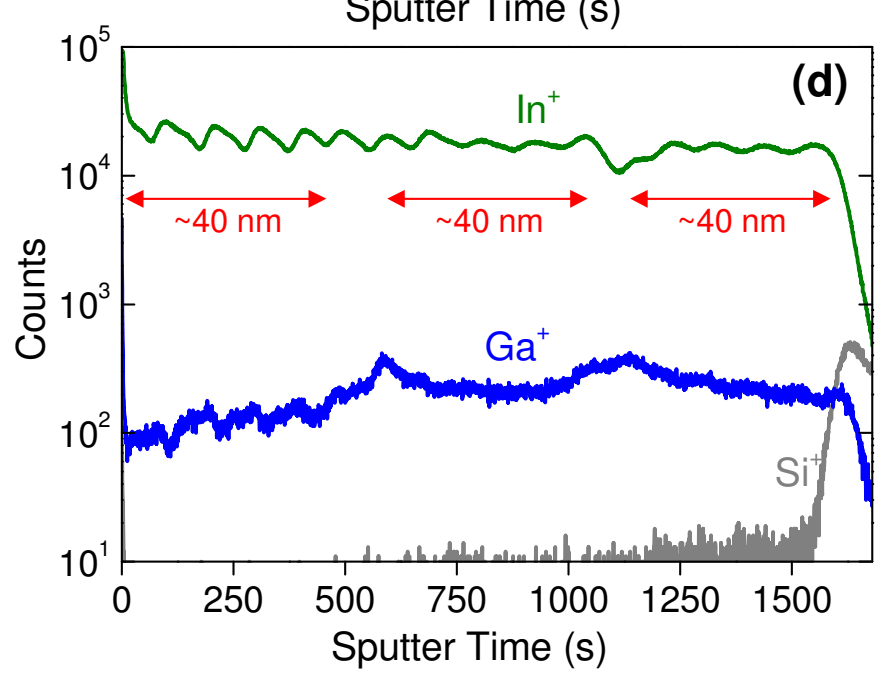

Figure 3. (a) Schematic representation of proposed multi-layer semiconducting oxide structure formed by sequential spin-casting of $\mathrm{In}_{2} \mathrm{O}_{3}, \mathrm{Ga}_{2} \mathrm{O}_{3}$ then $\mathrm{In}_{2} \mathrm{O}_{3}$ on polished Si. (b) Schematic Representation of similar structure formed from 5 semiconducting layers: $\operatorname{In}_{2} \mathrm{O}_{3}$, $\mathrm{Ga}_{2} \mathrm{O}_{3}, \mathrm{In}_{2} \mathrm{O}_{3}, \mathrm{Ga}_{2} \mathrm{O}_{3}$ then $\mathrm{In}_{2} \mathrm{O}_{3}$. Each distinct layer in each structure is formed from 5 sequential spin-casts of the relevant material. (c) Time-of-Flight Secondary Ion-Mass Spectroscopy (TOF-SIMS) depth profile of 3-layer oxide structure displayed in (a). (d) TOFSIMS depth profile of 5-layer oxide structure displayed in (b). The layer thicknesses shown in (c) and (d) are indicative and were estimated on the basis of the TEM data in Figure 1. 
(a)
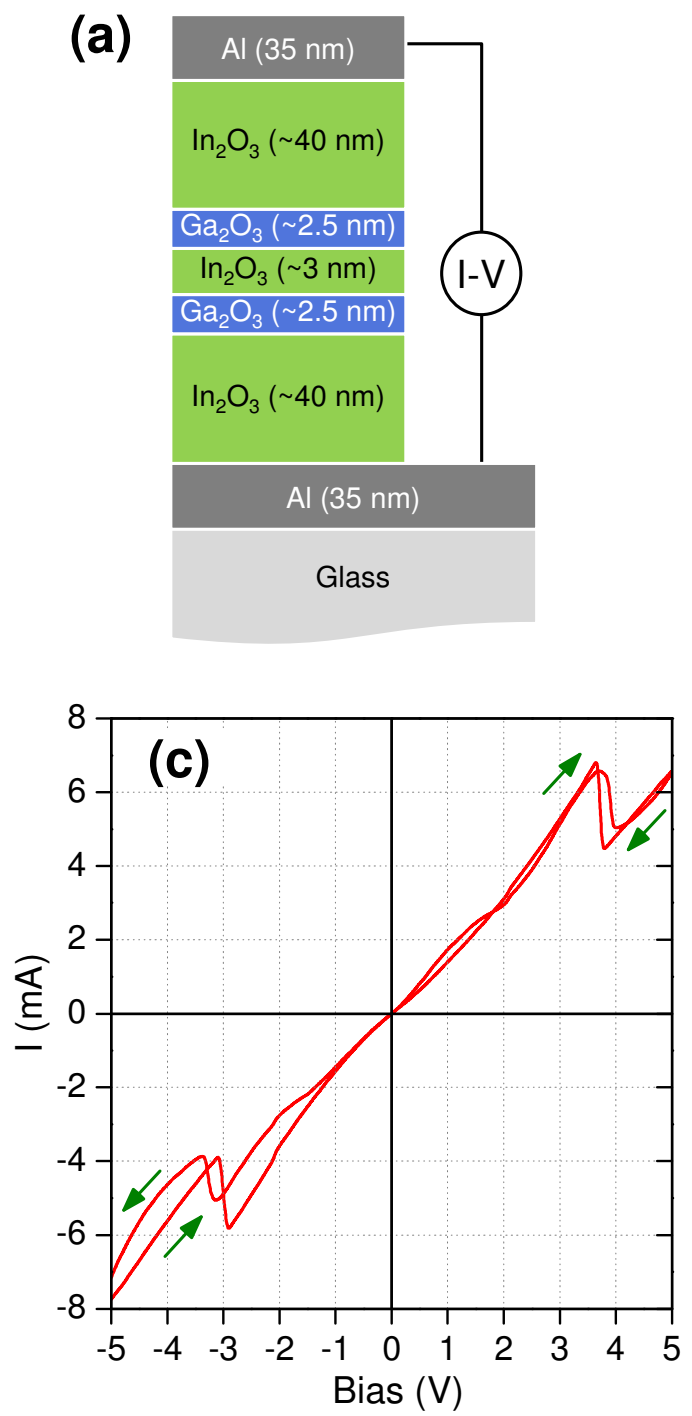

(b)
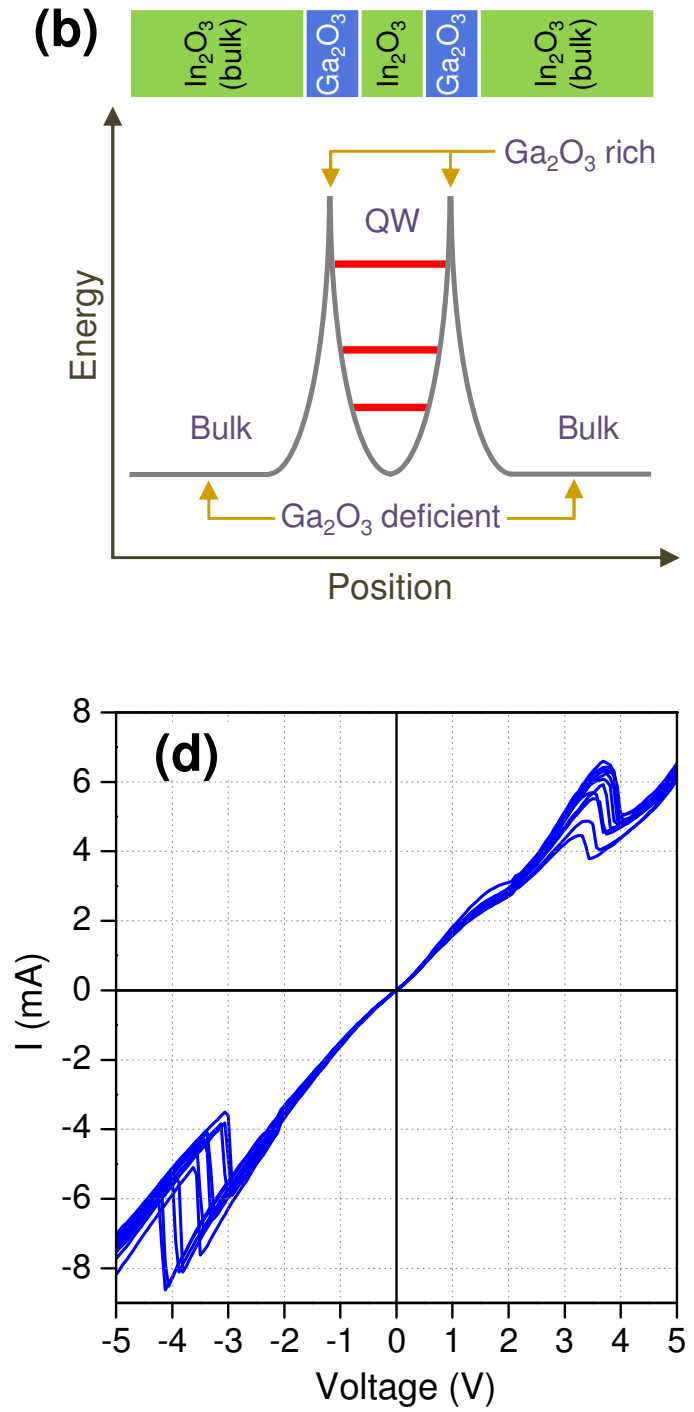

Figure 4. (a) Schematic representation of solution processed double-barrier resonanttunneling diode (RTD) structure. A very thin layer $(\sim 3 \mathrm{~nm})$ of $\mathrm{In}_{2} \mathrm{O}_{3}$ is confined between two $\mathrm{Ga}_{2} \mathrm{O}_{3}$-rich regions. Each $\mathrm{Ga}_{2} \mathrm{O}_{3}$-rich region is believed to have a higher conduction band minimum than the central $\operatorname{In}_{2} \mathrm{O}_{3}$ region, giving rise to a quantum well in the centre of the device. This quantum well is then sandwiched between two bulk $\operatorname{In}_{2} \mathrm{O}_{3}$ layers which act as electron "reservoirs". Evaporated aluminum contacts are present at either end of the device to make electrical contact with the bulk $\operatorname{In}_{2} \mathrm{O}_{3}$ layers. (b) Illustrative depiction of the conduction band of the structure described in (a). The red lines represent quantized sub-bands in the central $\mathrm{In}_{2} \mathrm{O}_{3}$ region. (c) Forward and reverse current-voltage (I-V) characteristics of a representative solution-processed $\operatorname{In}_{2} \mathrm{O}_{3} \mathrm{RTD}$, illustrated in (a). The device was measured at room temperature in ambient pressure $\mathrm{N}_{2}$. The device area was $0.0625 \mathrm{~mm}^{2}$. (d) $\mathrm{I}-\mathrm{V}$ sweeps of the same device measured repeatedly 10 times. The voltage at which NDC occurs in each repeated I-V sweep appears to be random. The latter is and most likely attributed to charge de/trapping at the critical oxide-oxide hetero-interfaces. 

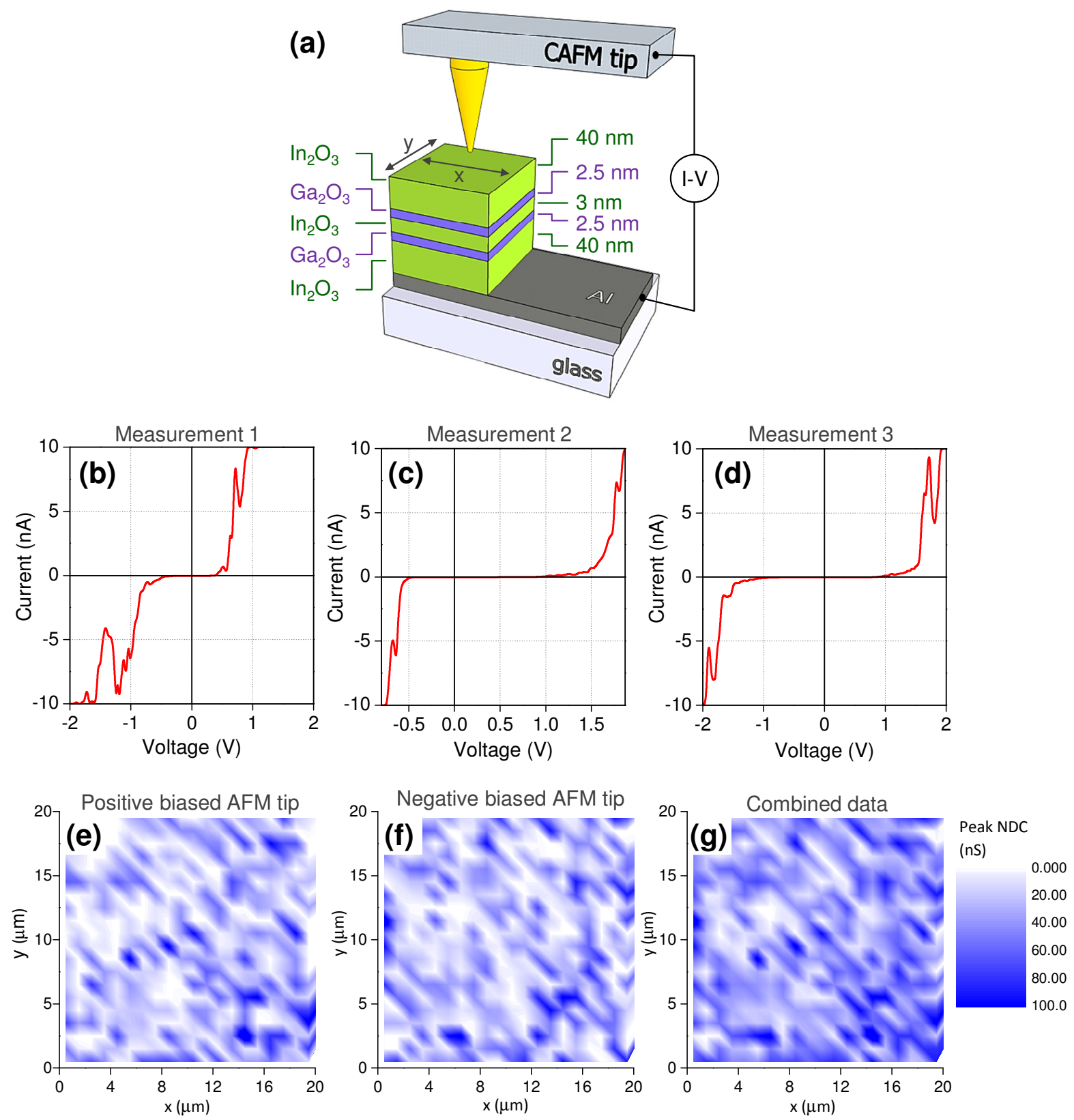

Figure 5. (a) Schematic representation of conducting atomic force microscopy (CAFM) measurement setup employed to characterize resonant-tunneling diode (RTD) structure. A voltage was applied between an evaporated bottom aluminum electrode and the CAFM cantilever. The current was then measured across the structure. (b-d) Example current-voltage characteristics measured using the setup illustrated in (a) with the cantilever at various positions on the sample surface. The compliance of the measurement setup was $10 \mathrm{nA}$ for all measurements. (e), (f) and (g) maximum negative differential conductivity (NDC) extracted from measured current-voltage characteristics as a function of position on the RTD surface for positive, negative and all applied voltages respectively. The maximum NDC at each position was calculated using 11-point differentiation. 


\section{Table of Contents Entry}

The existence of quantized energy states in ultra-thin, solution-processed layers of indium oxide is demonstrated. Layers with thickness below a critical value are observed to exhibit a characteristic widening of the optical band gap in strong agreement with calculated values. Sequential deposition of indium oxide and gallium oxide layers is employed to form doublebarrier resonant tunneling diodes exhibiting negative differential conductance under reverse and forward bias [Image].

\section{ToC Figure}
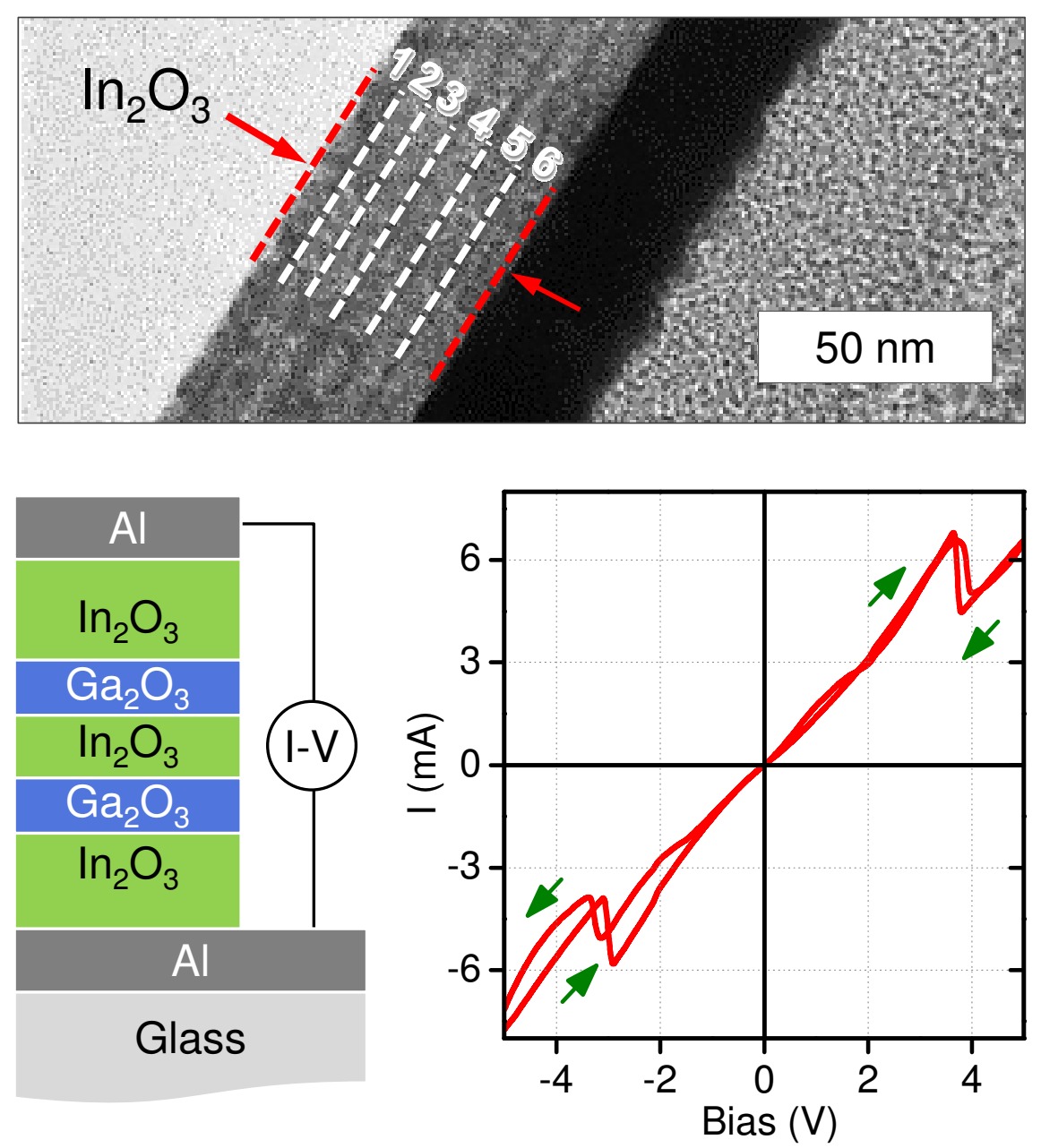


\section{Supporting Information}

\section{Energy Quantization in Solution-Processed Layers of Indium Oxide and Their Application in Resonant Tunneling Diodes}

John G. Labram, Neil D. Treat, Yen-Hung Lin, Claire H. Burgess, Martyn A. McLachlan Thomas D. Anthopoulos

\section{S1. Transmission electron microscopy (TEM)}

Figure S1 shows the same microscope image from Figure 1(c) in the main text at a higher resolution. The film was approximated to be $43 \mathrm{~nm}$ thick from this image and was formed from 6 sequential depositions of $\operatorname{In}_{2} \mathrm{O}_{3}$ on quartz, each of which is identifiable in Figure $\mathbf{S 1}$. The darker regions between spin-casts are believed to be regions of a different structural phase in the $\operatorname{In}_{2} \mathrm{O}_{3}$, induced during UV-ozone treatment applied between each deposition.

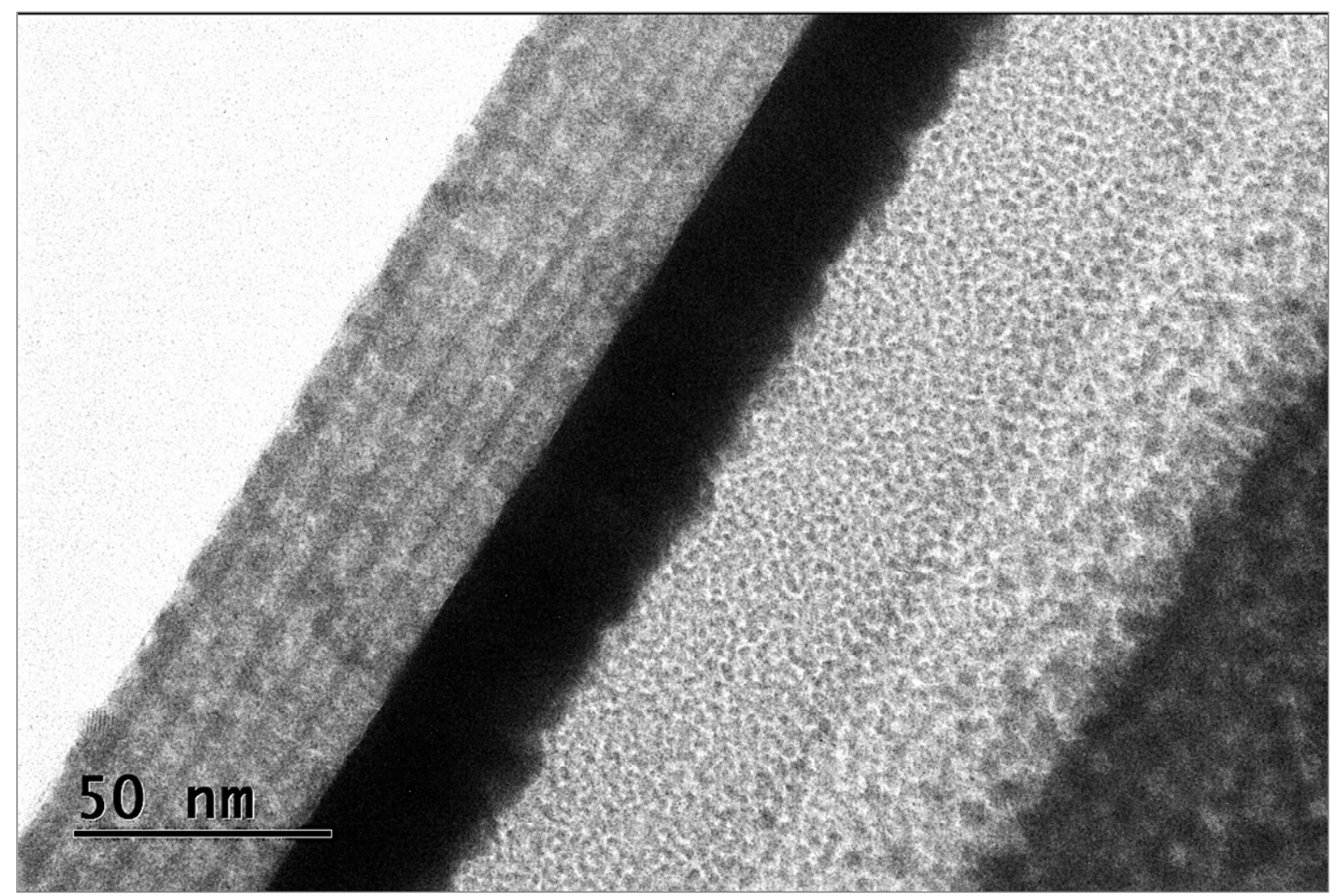


Figure S1. Transmission electron microscopy image of the cross-section of a spin-cast $\operatorname{In}_{2} \mathrm{O}_{3}$ layer deposited onto a quartz substrate. The light region on the left is the quartz substrate and the region adjacent is the $\mathrm{In}_{2} \mathrm{O}_{3}$ film. The regions to the right of the $\mathrm{In}_{2} \mathrm{O}_{3}$ film are capping layers. This film was formed by 6 sequential spin casts of $\operatorname{In}_{2} \mathrm{O}_{3}$. Between each spin cast, the film was annealed then treated with UV-ozone. The darker regions visible are the interfaces between each spin-cast and are interpreted to be regions of a different structural phase of $\mathrm{In}_{2} \mathrm{O}_{3}$.

\section{S2. Atomic force microscopy}

Figure S2 shows the surface topography of an $\operatorname{In}_{2} \mathrm{O}_{3}$ film on quartz, approximated to be $3 \mathrm{~nm}$ thick by TEM over several scan sizes, with the same central position. The film is clearly continuous over a large area and exhibits concentric lines. These are believed to be due to centrifugal forces on the semiconductor precursor solution during spin-casting.

Figure S2(f) shows the height standard deviation of several $\mathrm{In}_{2} \mathrm{O}_{3}$ films on quartz, extracted from the height distribution over a $5 \mu \mathrm{m} \times 5 \mu \mathrm{m}$ area. There is clearly a large spread in these values, but interestingly the films formed from multiple depositions of $\operatorname{In}_{2} \mathrm{O}_{3}$ are generally found to have a lower standard deviation. This suggests that depositing $\operatorname{In}_{2} \mathrm{O}_{3}$ on $\operatorname{In}_{2} \mathrm{O}_{3}$ leads to a planarization of the surface. 

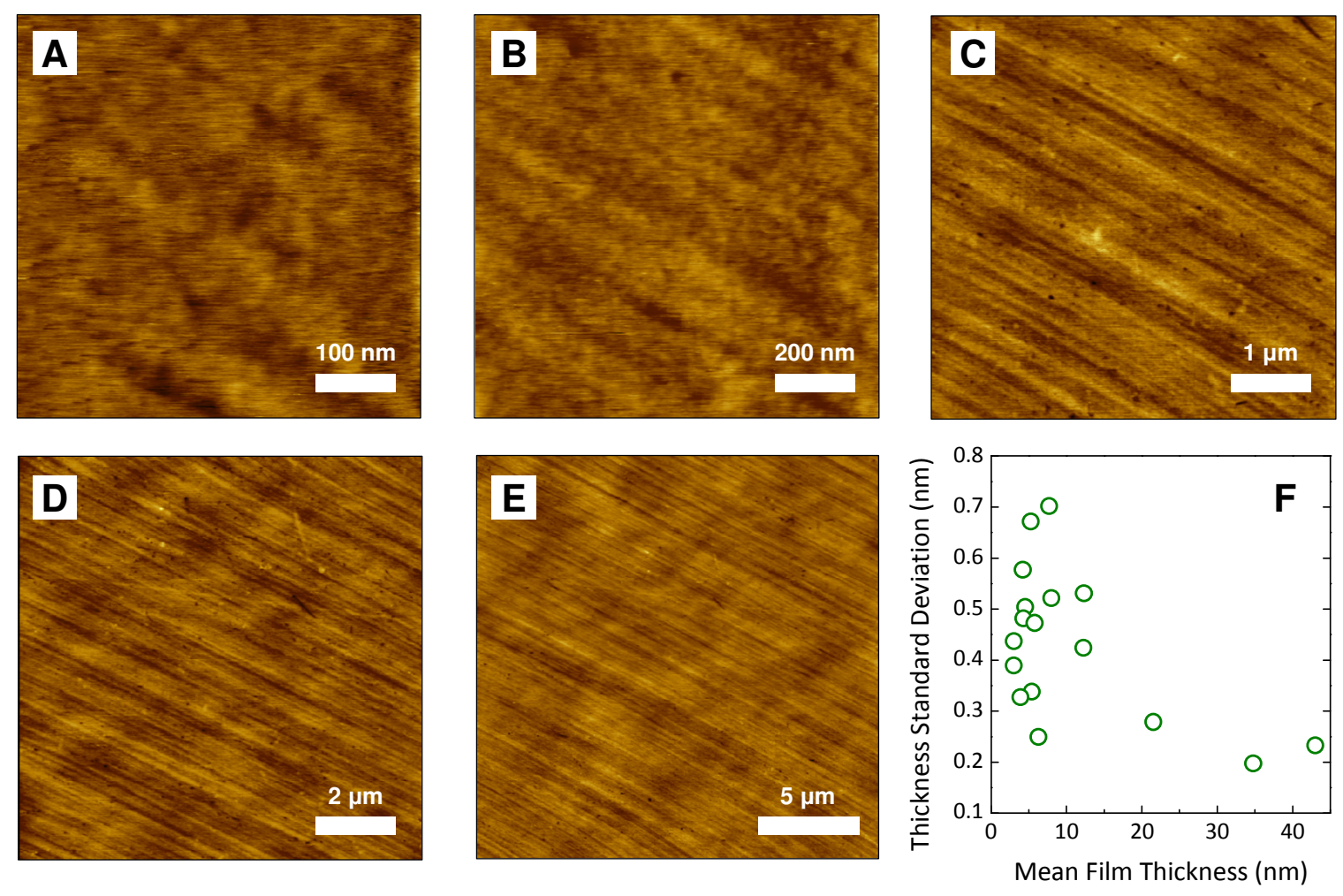

Figure S2. (a)-(e) Surface topography of $\mathrm{In}_{2} \mathrm{O}_{3}$ film with mean thickness of $3 \mathrm{~nm}$ measured using atomic force microscopy over various scan sizes. (f) Height standard deviation of several $\mathrm{In}_{2} \mathrm{O}_{3}$ films extracted from Gaussian fits to $5 \mu \mathrm{m} \times 5 \mu \mathrm{m}$ topography images as a function of mean film thickness.

\section{S3. Field-effect transistor (FET) measurements}

To further demonstrate the continuousness of these $\operatorname{In}_{2} \mathrm{O}_{3}$ films, several bottom gate, top contact (BGTC) field-effect transistors were fabricated on highly doped $\left(\mathrm{n}^{++}\right)$silicon wafers, acting as the common gate electrode, with a $400 \mathrm{~nm}$ thermally grown silicon dioxide layer as gate dielectric. The dielectric capacitance of the $\mathrm{SiO}_{2}$ layer was $8.6 \mathrm{nFcm}^{-2} \cdot \mathrm{In}_{2} \mathrm{O}_{3}$ films were spin-cast from the solutions described in Section S1.1. The as-spun samples were annealed at $200{ }^{\circ} \mathrm{C}$ for 30 minutes in air. $35 \mathrm{~nm}$ aluminum source and drain electrodes were then deposited via thermal evaporation under high vacuum through shadow masks at an average rate of $0.5 \AA \mathrm{s}^{-1}$. 
Electrical characterization was carried out at room temperature under ambient pressure in $\mathrm{N}_{2}$, using an Agilent B2902A semiconductor parameter analyzer. The mobility of charge carriers was estimated in the linear and saturation regimes using the gradual-channel approximation. ${ }^{1}$ All films were believed to have a mean film thickness of approximately $3 \mathrm{~nm}$. As is evident from Figure S3 such films give rise to good FET characteristics and extracted field-effect mobilities which are in agreement with previous reports on this system. ${ }^{2}$ Such characteristics require long-range (10's - 100's of $\mu \mathrm{m})$ film continuity.
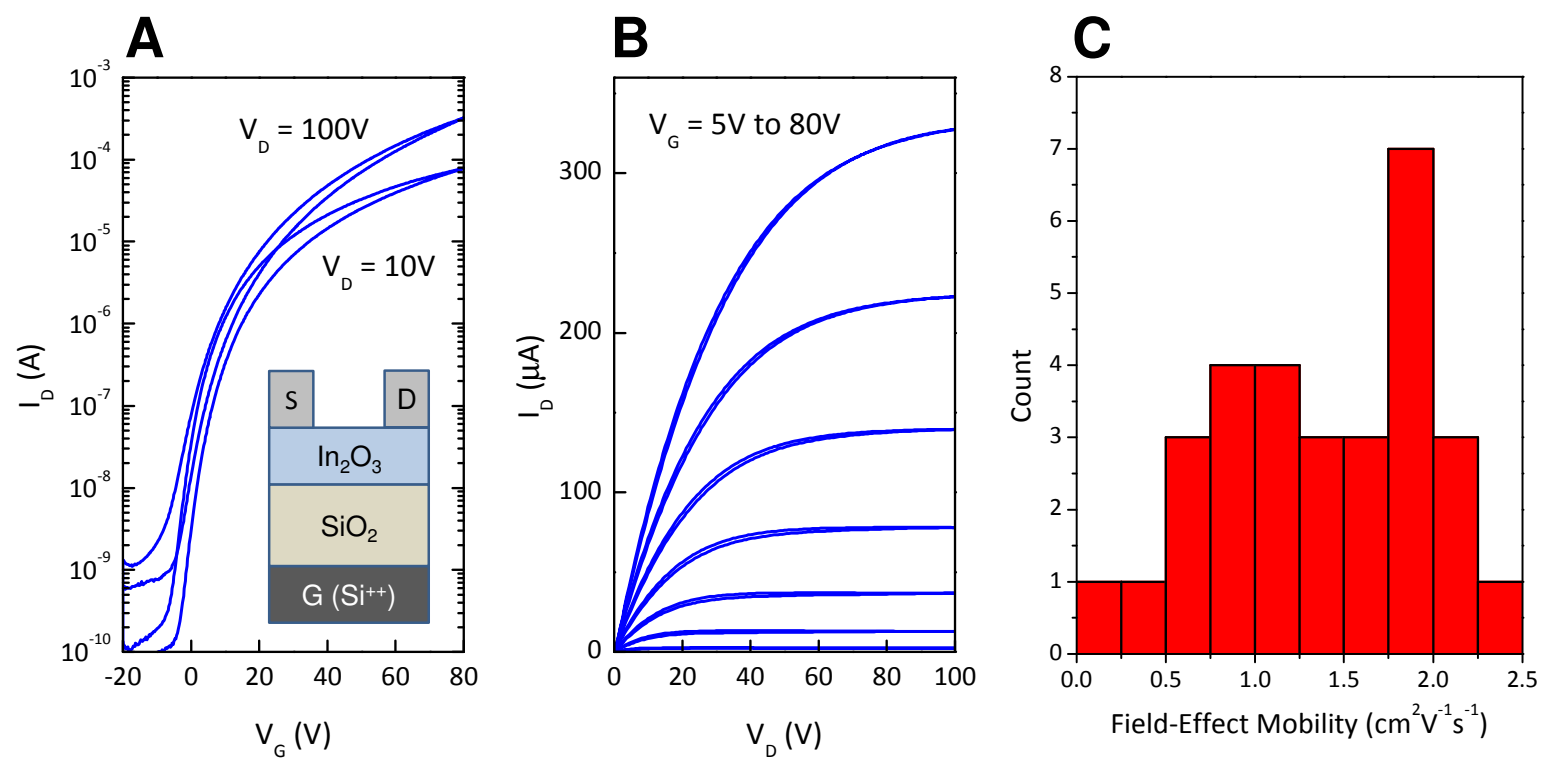

Figure S3. (a) Transfer characteristics of example $\operatorname{In}_{2} \mathrm{O}_{3}$ bottom-gate, top-contact (BGTC) thin-film transistor (TFT) with channel length of $100 \mu \mathrm{m}$ and width of $1 \mathrm{~mm}$. Inset: Schematic diagram of BGTC TFT structure. S and D label the aluminum source and drain electrodes respectively and G labels the gate electrode. (b) Output characteristics of same BGTC $\operatorname{In}_{2} \mathrm{O}_{3}$ TFT. (c) Linear field-effect mobility of several $\mathrm{In}_{2} \mathrm{O}_{3}$ BGTC TFTs. The $\operatorname{In}_{2} \mathrm{O}_{3}$ film is in all cases approximately $3 \mathrm{~nm}$ thick. All measurements carried out under ambient pressure $\mathrm{N}_{2}$.

\section{S4. Tauc analysis}

Tauc analysis ${ }^{3,4}$ is an optical technique used to approximate the band-gap of inorganic semiconductors. The technique entails plotting $(\alpha h v)^{X}$ against $h v$, then extrapolating the 
linear part of the plot to $(\alpha h v)^{X}=0 . \alpha$ is the optical absorbance of the material, $h v$ is the incident photon energy and $X$ is an exponent that depends on the nature of the semiconductor band-gap. For direct band-gap semiconductors $X=2$ is used, whilst for indirect band-gap semiconductors $X=1 / 2$ is used. Since the nature of the band gap in $\operatorname{In}_{2} \mathrm{O}_{3}$ is still under debate, ${ }^{5-7}$ we have here used both techniques. Figure S4 shows Tauc plots for $17 \operatorname{In}_{2} \mathrm{O}_{3}$ films using the assumption that the band-gap is direct, whilst Figure S5 shows the same data assuming the band-gap is indirect. Both sets of extracted band gaps are plotted in Figure 2(b) in the main text. 
Adv. Funct. Mater. (2016); DOI: 10.1002/adfm.201503732
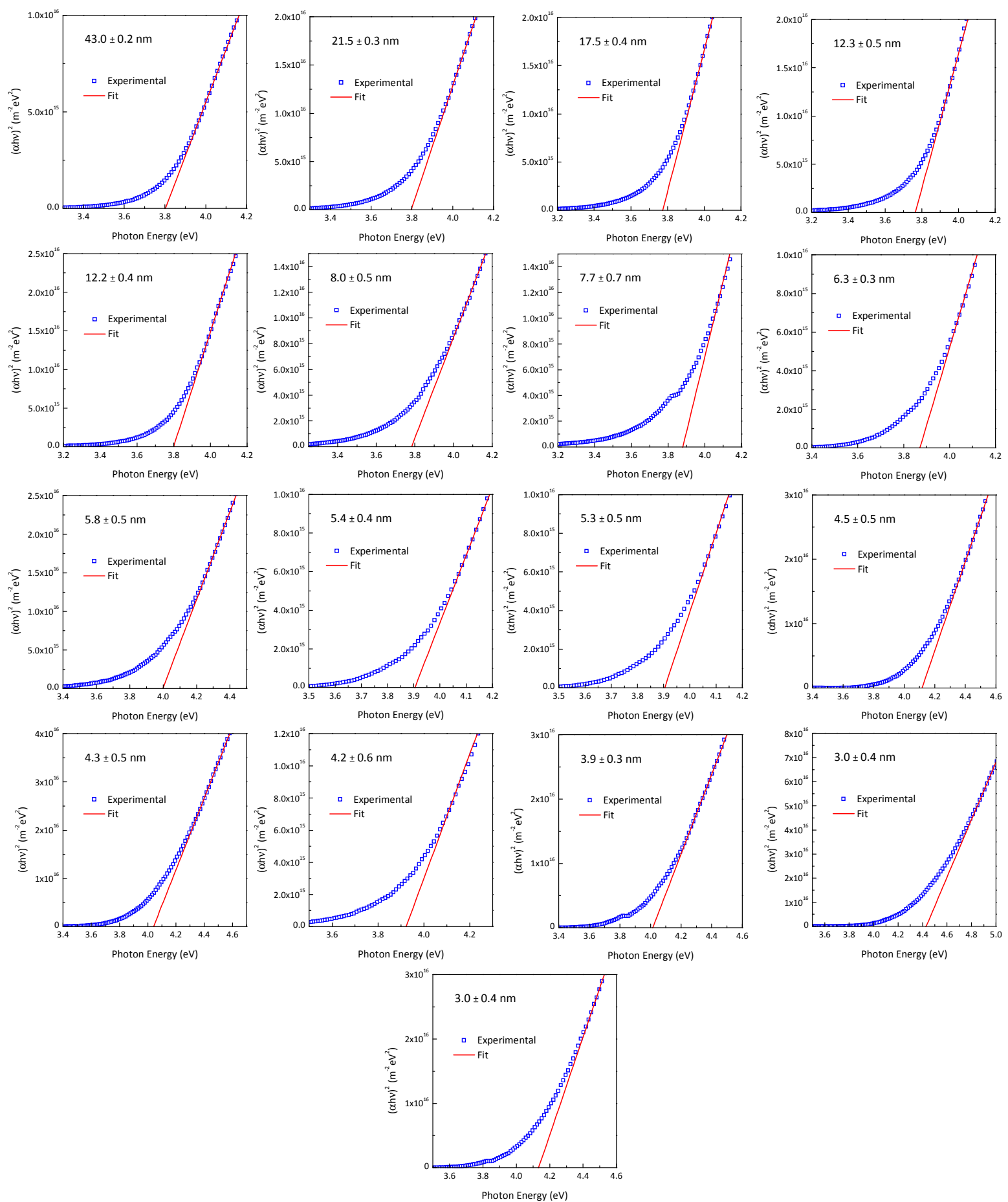

Figure S4. Tauc plots of $17 \mathrm{In}_{2} \mathrm{O}_{3}$ films of various thickness spin-cast onto quartz, evaluated assuming the band gap of $\operatorname{In}_{2} \mathrm{O}_{3}$ is direct. 
Adv. Funct. Mater. (2016); DOI: 10.1002/adfm.201503732
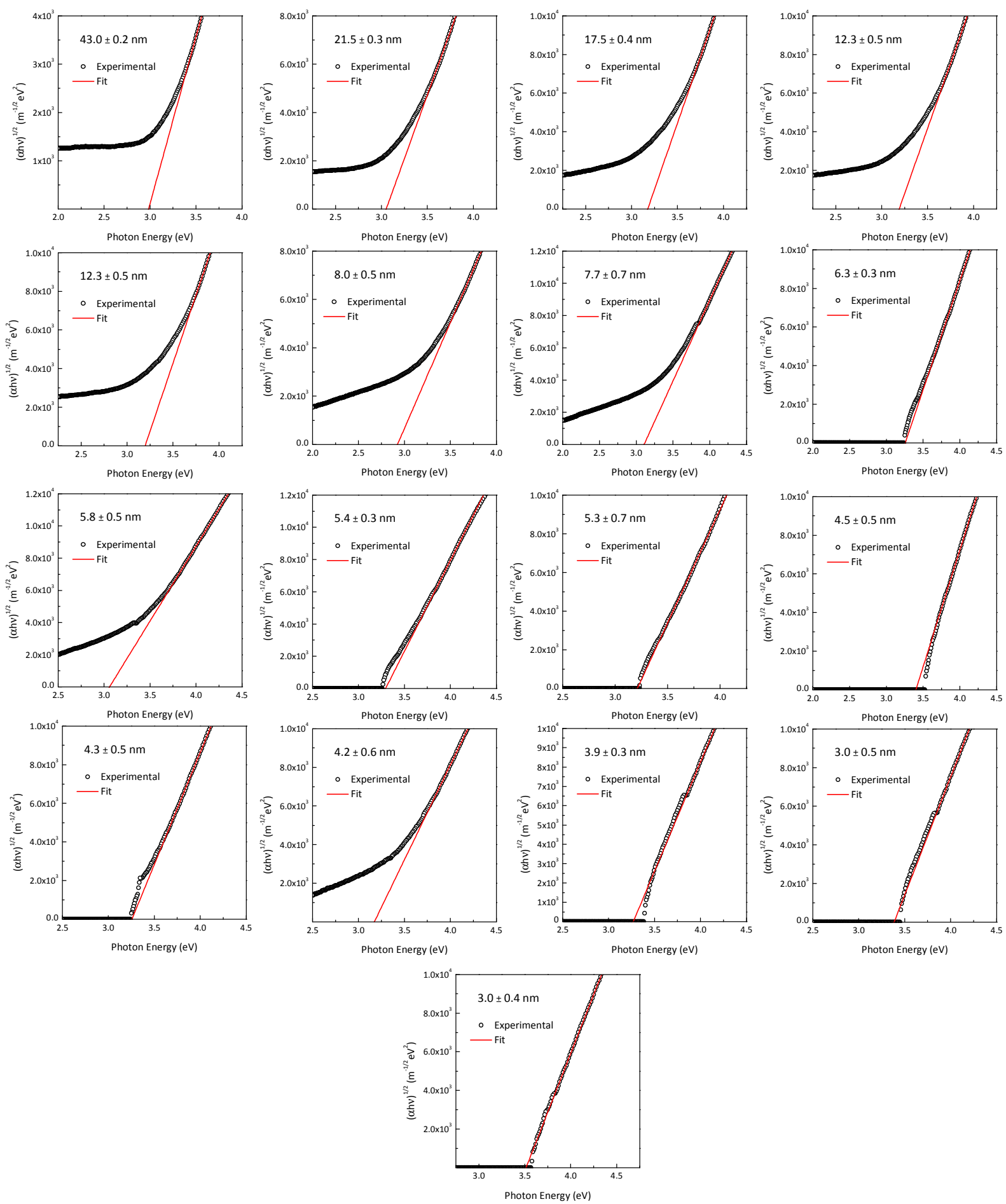

Figure S5. Tauc plots of $17 \mathrm{In}_{2} \mathrm{O}_{3}$ layers of various thickness spin-cast onto quartz, evaluated assuming the band gap of $\operatorname{In}_{2} \mathrm{O}_{3}$ is indirect. For ultra-thin layers $(<5 \mathrm{~nm})$, variation in the $(\alpha h v)^{1 / 2}$ values for energies below the band edge are most likely attributed to differences in the layer surface roughness (and hence scattering), integration time used for each measurement, and small changes in the sample/layer geometry (difference in thickness of quartz substrates used etc.). 


\section{S5. One-dimensional (1D) quantum well with finite roughness}

When considering quantized sub-bands in structurally rough semiconductors one is forced to consider the probability that a carrier locally experiences a quantum well of a certain width, given the average width and width standard deviation of the well generally. This is contrast to atomically flat quantum wells, such as those formed by molecular beam epitaxy or pulsed laser deposition where one can assume all carriers experience the same sized-well. To evaluate this distribution we employ an analysis similar to that described in our previous report. ${ }^{8}$

If we define the dimension perpendicular to the substrate surface as $z$, then the energy of conduction band and valence band states available to electrons and holes respectively, confined to an infinite quantum well can be described by: ${ }^{9}$

$$
\begin{aligned}
& E_{n, e}=E_{x y}+\frac{n^{2} h^{2}}{8 m_{e}^{*} L^{2}} \\
& E_{n, h}=E_{x y}+\frac{n^{2} h^{2}}{8 m_{h}^{*} L^{2}}
\end{aligned}
$$

Here, $E_{x y}$ is the energy associated with the carrier in the (unconfined) $x y$-plane, $n$ is a positive integer, $h$ is the Planck Constant, $m_{e}^{*}$ is the effective mass of electrons in the semiconductor, $m_{h}^{*}$ is the effective mass of holes in the semiconductor and $L$ is the thickness of the quantum well in the $z$-direction. As $L$ is reduced the energy of the first electron state $(n=1)$, and hence the conduction band minimum (CBM), increases. Similarly the energy of the first hole state ( $n$ $=1$ ), and hence the valence band maximum (VBM), decreases. The energy of the first allowed transition from valance band to the conduction band in-turn increases, resulting in a blue-shift in the optical absorption spectrum of the film: ${ }^{10}$ 


$$
\Delta E_{G}=\frac{h^{2}}{8 L^{2}}\left(\frac{1}{m_{e}^{*}}+\frac{1}{m_{h}^{*}}\right)
$$

We have here modeled single layers of thin $\operatorname{In}_{2} \mathrm{O}_{3}$ on quartz as such infinite quantum wells. Since quartz is a very wide band-gap semiconductor, this approximation is reasonable. Finite quantum well energies were calculated using known techniques ${ }^{11}$ (data not shown), but the results were found to be negligibly different from those evaluated using the above infinite quantum-well approximation.

For structurally rough semiconductors it is appropriate to describe the thickness of the quantum well experienced by an incident photon as having a probability distribution $f\left(\mu_{L}, \sigma_{L}\right)$, where $\mu_{L}$ is the mean well width and $\sigma_{L}$ is the well width standard deviation. If we assume the film thickness is distributed as a Gaussian, ${ }^{8}$ then we can say that for a given $\mu_{L}$ and $\sigma_{L}$ the probability of an incident photon encountering a well of energy $E_{n}$ is given by:

$$
f\left(E_{n}, \mu_{n}, \sigma_{L}\right)=\frac{1}{\sigma_{L} \sqrt{2 \pi}} \exp \left[\frac{1}{2 \sigma_{L}^{2}}\left(\frac{n h \mu_{L}}{\sqrt{2 m^{*} E_{n}}}-\frac{n^{2} h^{2}}{8 m^{*} E_{n}}-\mu_{L}^{2}\right)\right]
$$

This distribution is plotted in Figure S6 for the first four conduction band and valence band states of an infinite quantum well with $\mu_{L}=2 \mathrm{~nm}, m_{e}^{*}=0.3 m_{e}$ and $m_{h}^{*}=0.6 m_{e}$ (the known values for crystalline $\left.\mathrm{In}_{2} \mathrm{O}_{3}\right)^{12}$, and a range of example standard deviations. As one would expect, as the semiconductor roughness increases the sub-bands broaden, but regions of forbidden energies clearly exist. 


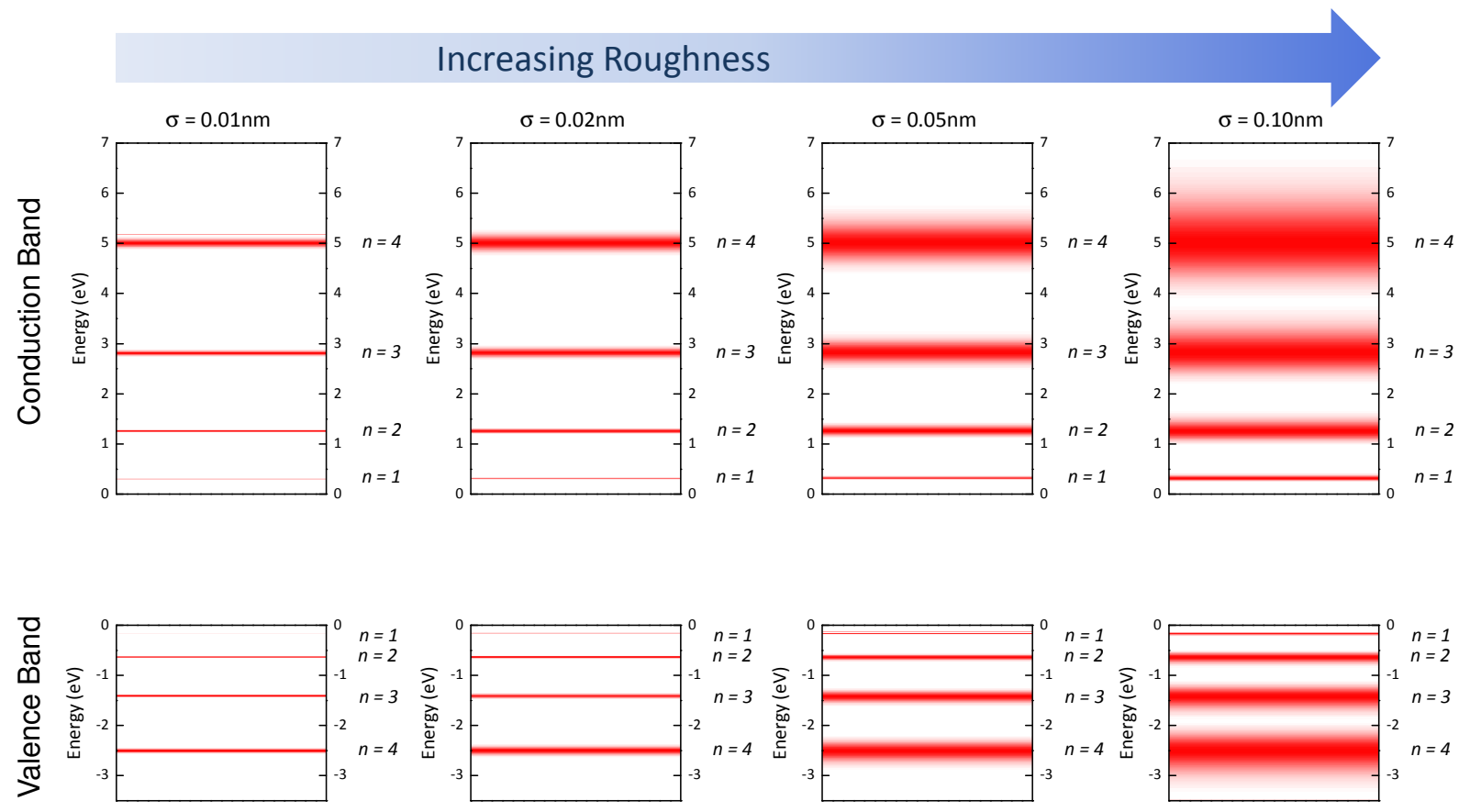

Figure S6. Probability distributions of first 4 conduction band (top) and valence band (bottom) sub-bands in infinite $\operatorname{In}_{2} \mathrm{O}_{3}$ quantum well with various height standard deviations $\left(\sigma_{L}\right)$, calculated using equation S3. Energies with the highest probability for a given sub-band are red and energies with a probability of zero are white. The mean well width $\left(\mu_{L}\right)$ was $2 \mathrm{~nm}$ in each case and the effective electron and hole masses were $m_{e}{ }_{e}=0.3 m_{e}$ and $m_{h}{ }_{h}=0.6 m_{e}$ respectively, where $m_{e}$ is the rest mass of an electron in a vacuum.

\section{S6. Time-of-flight secondary ion-mass spectroscopy}

Time-of-flight secondary ion-mass spectroscopy (TOF-SIMS) was carried out on 5 different samples. Schematic representations of the 5 samples studied are shown in Figures S7(a-e). Each of the semiconductor layers depicted in Figure S7 corresponds to 5 sequential depositions of the relevant semiconductor. For example the structure in Figure S7(a) was formed by 5 sequential spin-casts of $\operatorname{In}_{2} \mathrm{O}_{3}$ onto polished Si, the structure in Figure S7(b) was formed by 5 sequential spin-casts of $\operatorname{~}_{2} \mathrm{O}_{3}$ onto polished $\mathrm{Si}$ followed by 5 sequential spincasts of $\mathrm{Ga}_{2} \mathrm{O}_{3}$ onto the $\mathrm{In}_{2} \mathrm{O}_{3}$, and so on. After each individual spin-cast the samples were annealed for 30 minutes at $200^{\circ} \mathrm{C}$, followed by UV-ozone treatment before the next 
deposition. The corresponding depth profiles as measured using TOF-SIMS are shown in Figures S7(f-j).
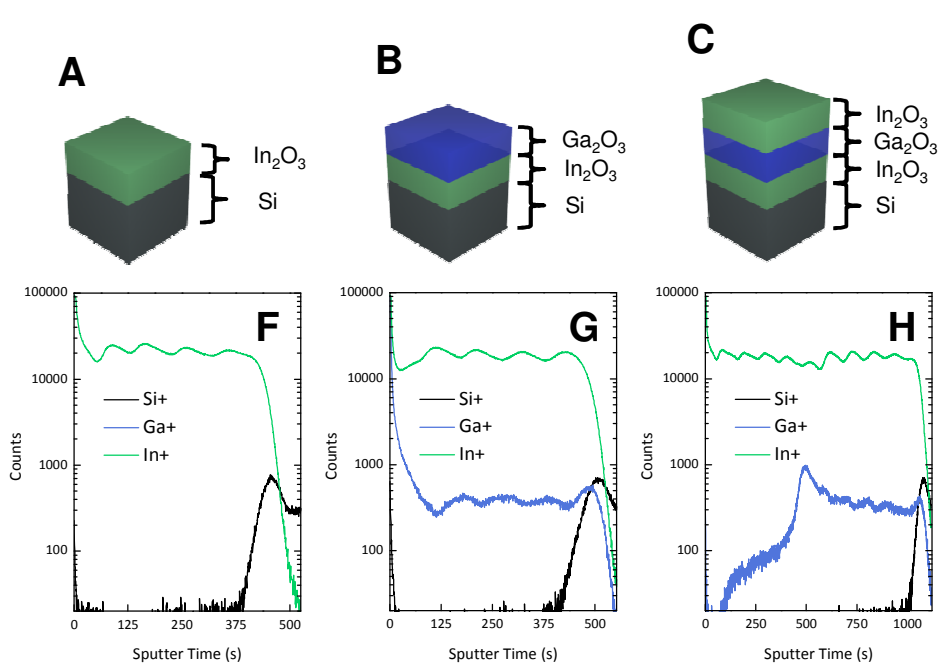

D
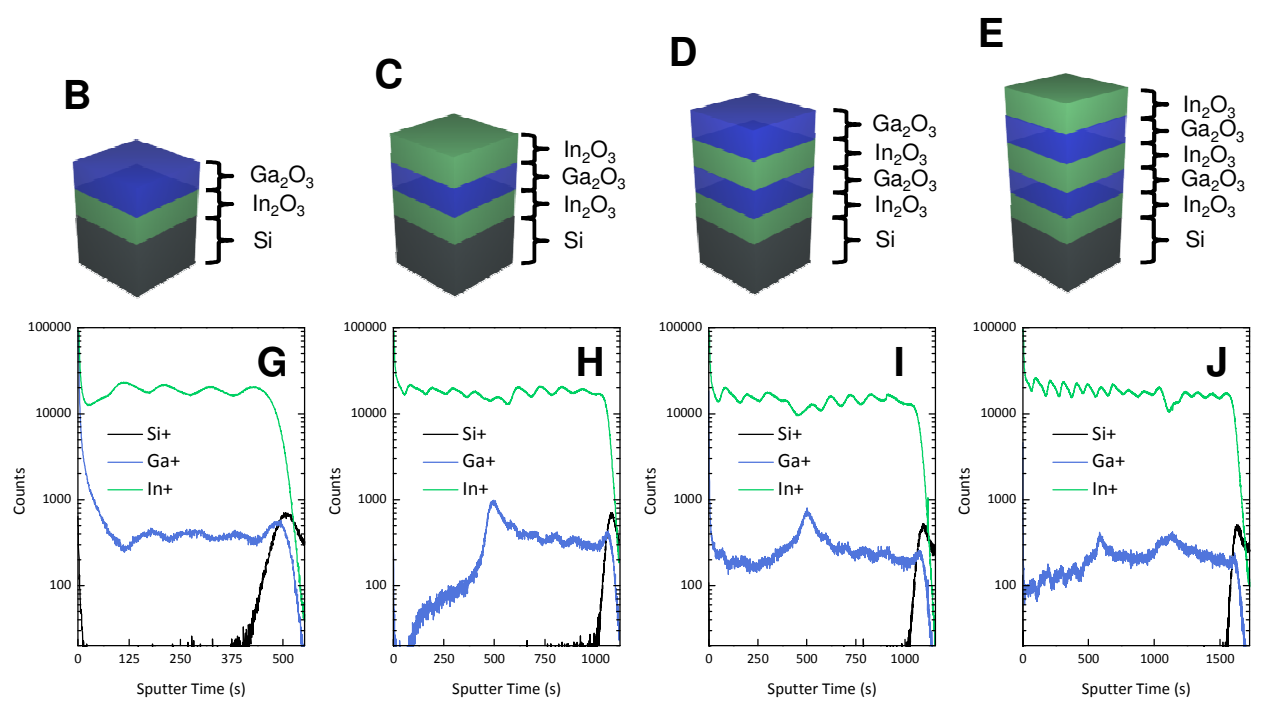

Figure S7. (a-e) Schematic representation of proposed structures studied using time-of-flight secondary ion-mass spectroscopy (TOF-SIMS). Each semiconductor layer was formed by 5 sequential spin-casts and subsequent anneals. Although the thickness of each layer is not known, these can be estimated directly from the data by assuming the first $\operatorname{In}_{2} \mathrm{O}_{3}$ layer is approximately $40 \mathrm{~nm}$-thick (verified by TEM measurements). (f-j) TOF-SIMS depth profiles of $\mathrm{Si}^{+}, \mathrm{Ga}^{+}$and $\mathrm{In}^{+}$ions from structures displayed in (a-e) respectively.

From this data it appears that the deposition of $\mathrm{Ga}_{2} \mathrm{O}_{3}$ leads to a local alloying of the $\operatorname{In}_{2} \mathrm{O}_{3}$ rather than chemically sharp interfaces layers. For example, the structures with $\mathrm{Ga}_{2} \mathrm{O}_{3}$ at the top appear to show a very high Ga-concentration that drops-off with depth. The similarity in total sample thickness between Figures S7(f) and (g) and Figures S7(c) and (d) give further weight to this interpretation. The nature of the Ga profiles in these figures also suggests that a temperature-activated diffusion process may be responsible. Figure S7(h) is particularly interesting since the Ga concentration below the peak is substantially higher than that above the peak. This could well be due to the $\mathrm{Ga}_{2} \mathrm{O}_{3}$ diffusing down during the annealing steps before the top $\mathrm{In}_{2} \mathrm{O}_{3}$ layers were present. 
A notable feature in all 5 of these plots is the apparent oscillation in the In signal with depth. On closer inspection it turns out that the number of oscillations corresponds exactly to the number of $\operatorname{In}_{2} \mathrm{O}_{3}$ spin-casts in every structure. Figure $\mathbf{S 8}$ shows a TOF-SIMS profile of the $\mathrm{In}_{2} \mathrm{O}_{3}$ film on polished $\mathrm{Si}$, with two additional molecules plotted $\left(\mathrm{Cs}_{2} \mathrm{InO}\right.$ and $\left.\mathrm{Cs}_{2} \mathrm{InO}_{2}\right)$. These signals clearly oscillate in anti-phase to the In signal, and the total counts for all ions / molecules is constant as a function of depth (data not shown). As described in the experimental section of the main text, the sputter beam for our system employs Cs ions, hence the substantial signals observed. It is interesting that Cs appears to preferentially alloy with $\mathrm{In}_{2} \mathrm{O}_{3}$ in the regions between spin-casts. This suggests that the structural phase in these regions differs from the rest of the structure, in agreement with the TEM data presented in

\section{Figure S1.}

A

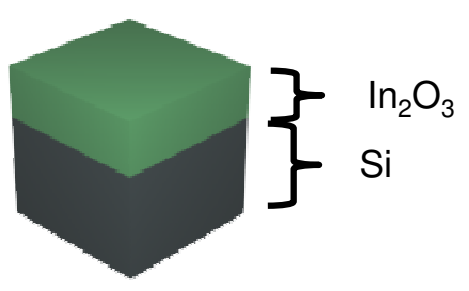

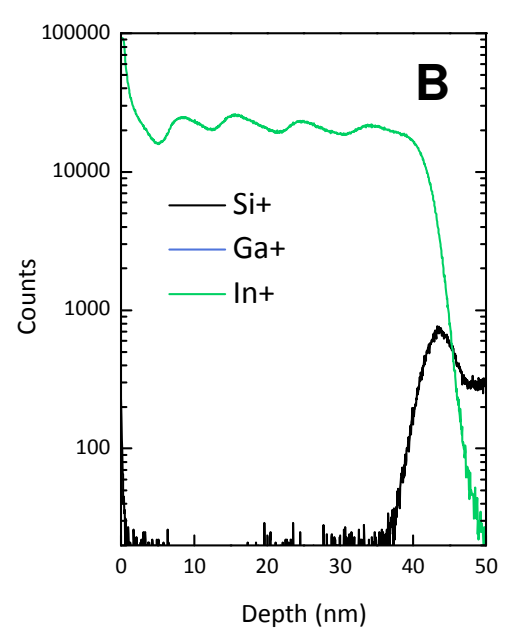

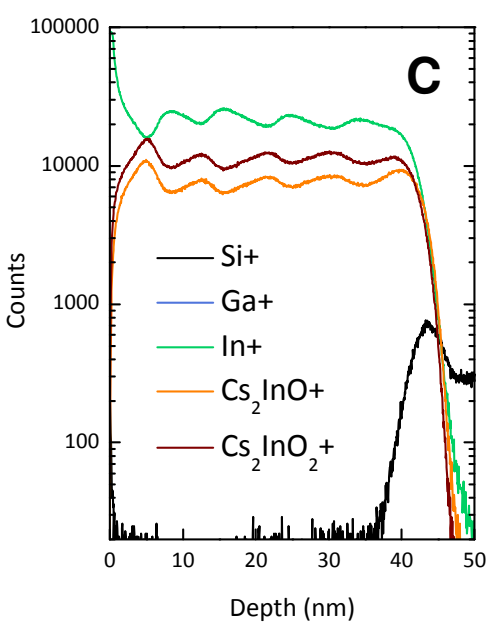

Figure S8. (a) Schematic representation of structure studied using time-of-flight secondary ion-mass spectroscopy (TOF-SIMS). The $\mathrm{In}_{2} \mathrm{O}_{3}$ layer was formed via 5 sequential spin-casts and subsequent anneals. (b) TOF-SIMS depth profile of $\mathrm{Si}^{+}, \mathrm{Ga}^{+}$and $\mathrm{In}^{+}$ions from structure displayed in (a). (c) TOF-SIMS depth profile of same structure, but also including counts for molecules with In and Cs constituents. Cs is the sputter gun element of the TOF-SIMS system employed in this study. 


\section{S7. Conducting atomic force microscopy correlation analysis}

Figures S9(a-b) show the spatial maps of peak negative differential conductance (NDC) from

Figure 5(e-g) in the main text. These plots were measured by employing conducting atomic force microscopy (CAFM) to measure many current-voltage (IV) curves as a function of surface position, then extracting the peak NDC at each position. In an attempt to extract quantitative information from this data, we have here evaluated the correlation between the existence of NDC under applied positive voltages and under applied negative voltages.
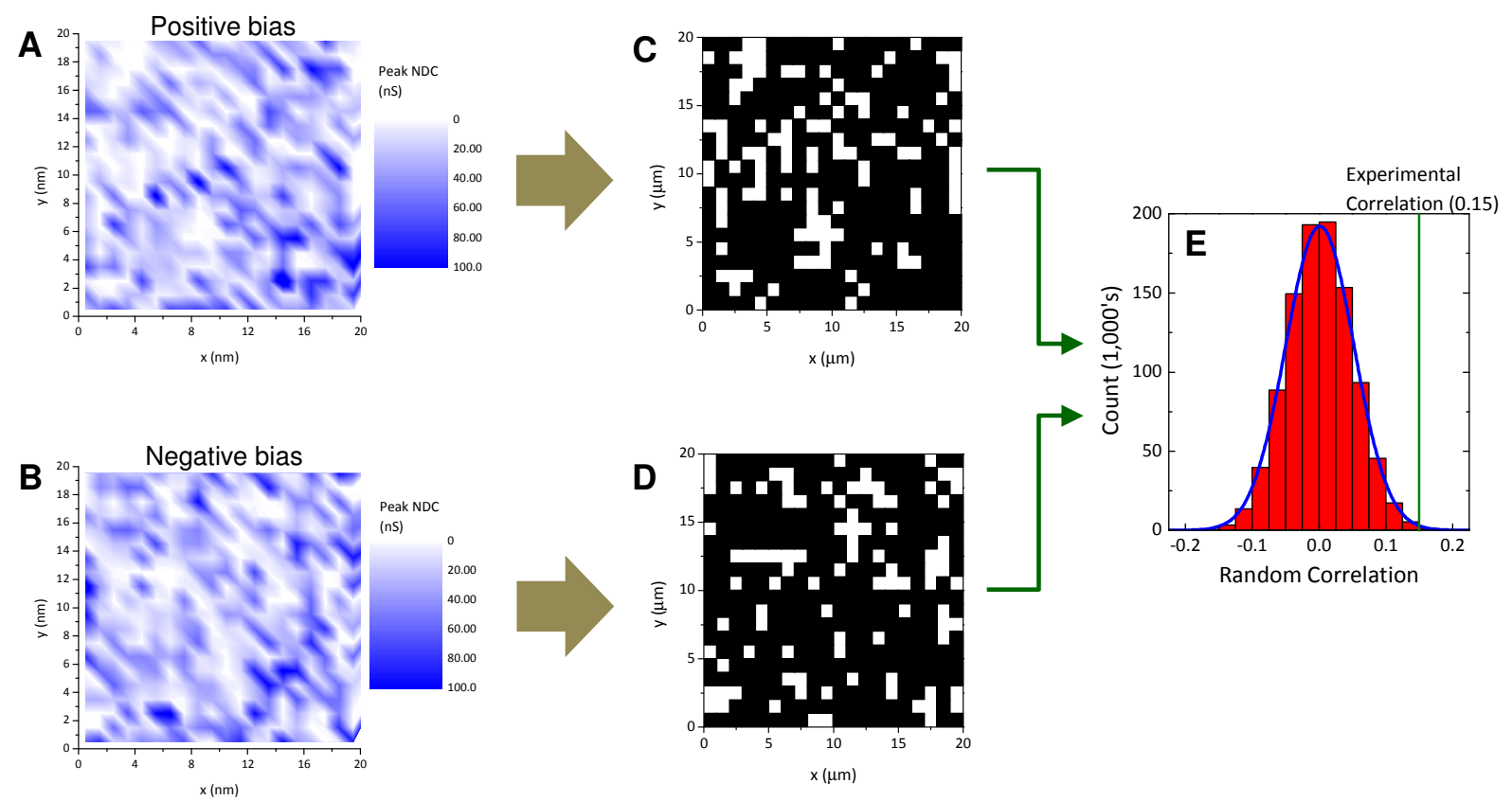

Figure S9. (a-b) Maximum negative differential conductivity (NDC) extracted from measured current-voltage characteristics as a function of position on the RTD surface for positive and negative voltages respectively. The maximum NDC at each position was calculated algorithmically using 11-point differentiation. (c) and (d) Binary maps of the data from (a) and (b) respectively, defined as " 1 " (black) when the peak NDC was $\geq 5 \mathrm{nS}$ and " 0 " (white) when the NDC was $<5$ nS. (e) Correlation evaluated using Equation S4 between the data shown in (c) and (d) after the 1's and 0's were randomly shuffled 1,000,000 times. The solid line is a normal distribution fitted to the calculated data with a standard deviation of $\sigma=0.05$. The black line shows the experimental correlation $(+0.155)$, evaluated between $(c)$ and (d) without being shuffled. 
To define NDC we have here said that any position that exhibits a peak NDC $\geq 5 \mathrm{nS}$ represents a binary " 1 " and any position that exhibits a peak NDC $<5 \mathrm{nS}$ represents a binary " 0 ". Binary maps for positive and negative applied voltages are represented in Figures S9(c-d) respectively, with black positions representing 1's and white positions representing 0's.

The correlation between two random variables $X$ and $Y$ is given as:

$$
\rho_{X Y}=\frac{\sigma_{X Y}}{\sigma_{X} \sigma_{Y}}
$$

Where $\sigma_{X Y}$ is the covariance of the variables $X$ and $Y$, and $\sigma_{X}$ and $\sigma_{Y}$ are the standard deviations of $X$ and $Y$ respectively. The statistical covariance is defined by:

$$
\sigma_{X Y}=\frac{1}{N-1} \sum_{i=1}^{N}\left(x_{i}-\mu_{X}\right)\left(y_{i}-\mu_{Y}\right)
$$

Here $N$ is the number of data points, $x_{i}$ is the $i^{\prime}$ th data point in the data $X, y_{i}$ is the $i^{\prime}$ th data point in the data $Y, \mu_{X}$ is the mean of the data $X$ and $\mu_{X}$ is the mean of the data $Y$.

For our analysis each surface position corresponds to a data point $i$, and values measured under positive applied voltages belong to the data set $X$ and values measured under negative applied voltages belong to the data set $Y$. By applying Equations S4 and S5 to the data in Figures S9(c-d) the statistical correlation was evaluated to be +0.155 . A positive correlation suggests that if NDC is observed in the first quadrant, it will on average also be observed in the third quadrant, and vice-versa.

To understand the significance of our evaluated correlation a simple Monte-Carlo simulation was carried out. The simulation took the binary maps from Figures S9(c-d), randomly shuffled up the 1's and 0's (whilst keeping the respective number of each constant) and evaluated the correlation. This was repeated 1,000,000 times. The resulting distribution in 
calculated correlation values between these random data sets is plotted in Figure S9(e). The solid line in Figure S9(e) is a normal distribution fitted to the calculated results. The standard deviation of this fit is 0.05 hence our experimental value is greater than three standarddeviations from the mean. This suggests that the value we observe experimentally is very unlikely to be due to chance alone.

\section{SI References}

1. Zaumseil, J.; Sirringhaus, H. Chemical Reviews 2007, 107, (4), 1296-1323.

2. Lin, Y.-H.; Faber, H.; Labram, J. G.; Stratakis, E.; Sygellou, L.; Kymakis, E.; Hastas, N. A.; Li, R.; Zhao, K.; Amassian, A.; Treat, N. D.; McLachlan, M.; Anthopoulos, T. D. Advanced Science 2015, 1500058.

3. Tauc, J.; Grigorovici, R.; Vancu, A. physica status solidi (b) 1966, 15, (2), 627-637.

4. Tauc, J. Materials Research Bulletin 1968, 3, (1), 37-46.

5. Erhart, P.; Klein, A.; Egdell, R. G.; Albe, K. Physical Review B 2007, 75, (15), 153205.

6. Walsh, A.; Da Silva, J. L. F.; Wei, S.-H.; Körber, C.; Klein, A.; Piper, L. F. J.; DeMasi, A.; Smith, K. E.; Panaccione, G.; Torelli, P.; Payne, D. J.; Bourlange, A.; Egdell, R. G. Physical Review Letters 2008, 100, (16), 167402.

7. King, P. D. C.; Veal, T. D.; Fuchs, F.; Wang, C. Y.; Payne, D. J.; Bourlange, A.; Zhang, H.; Bell, G. R.; Cimalla, V.; Ambacher, O.; Egdell, R. G.; Bechstedt, F.; McConville, C. F. Physical Review B 2009, 79, (20), 205211.

8. Labram, J. G.; Lin, Y.-H.; Zhao, K.; Li, R.; Thomas, S. R.; Semple, J.; Androulidaki, M.; Sygellou, L.; McLachlan, M.; Stratakis, E.; Amassian, A.; Anthopoulos, T. D. Advanced Functional Materials 2015, 25, (11), 1727-1736.

9. Hook, J. R.; Hall, H. E., Solid State Physics. Wiley: 1991.

10. Dingle, R.; Wiegmann, W.; Henry, C. H. Physical Review Letters 1974, 33, (14), 827-830.

11. Weisbuch, C.; Vinter, B., Quantum Semiconductor Structures: Fundamentals and Applications. Academic Press: 1991.

12. Hamberg, I.; Granqvist, C. G. Journal of Applied Physics 1986, 60, (11), R123-R160. 